\title{
The Psychopharmacology of Effort-Related Decision Making: Dopamine, Adenosine, and Insights into the Neurochemistry of Motivation
}

\author{
John D. Salamone, Mercè Correa, Sarah Ferrigno, Jen-Hau Yang, Renee A. Rotolo, and Rose E. Presby \\ Department of Psychological Sciences, University of Connecticut, Storrs, Connecticut (J.D.S., S.F., J.-H.Y., R.A.R., R.E.P.); and \\ Area de Psicobiologia, Universitat de Jaume I, Castelló, Spain (M.C.)
}

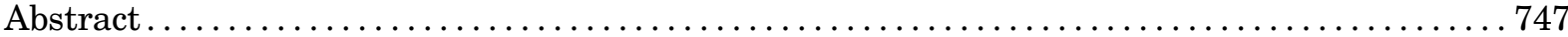

I. Introduction: Motivational Processes and Psychopharmacology.................... 747

II. Neural Circuits and Transmitters Mediating Effort-Based Choice: Mesolimbic Dopamine .... 748

III. Behavioral Effects of Dopaminergic Manipulations on Effort-Related Tasks Are Not Due to

Broad or General Changes in Reward, Temporal Processing, or Motor Incapacity .......... 750

IV. What Fundamental Processes Underlie the Low-Effort Bias Induced by Interference with

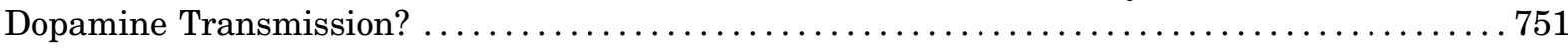

V. Neural Circuits and Transmitters Mediating Effort-Based Choice: Adenosine, GABA, and Nondopaminergic Components of the Circuit .............................. 753

VI. Clinical Implications: Targeting Drugs for the Potential Treatment of Effort-Based

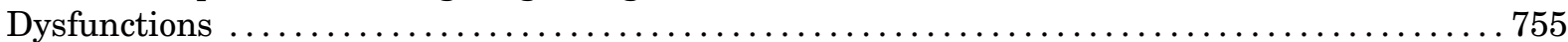

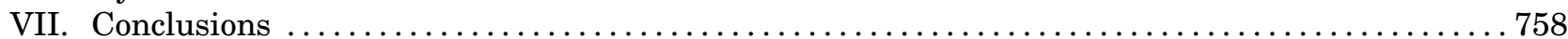

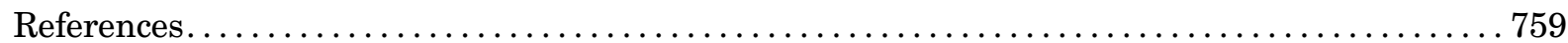

Abstract__Effort-based decision making is studied using tasks that offer choices between high-effort options leading to more highly valued reinforcers versus loweffort/low-reward options. These tasks have been used to study the involvement of neural systems, including mesolimbic dopamine and related circuits, in effortrelated aspects of motivation. Moreover, such tasks are useful as animal models of some of the motivational symptoms that are seen in people with depression, schizophrenia, Parkinson's disease, and other disorders. The present review will discuss the pharmacology of effort-related decision making and will focus on the use of these tasks for the development of drug treatments for motivational dysfunction. Research has identified pharmacological conditions that can alter effort-based choice and serve as models for depression-related symptoms (e.g., the vesicular monoamine transport-2 inhibitor tetrabenazine and proinflammatory cytokines). Furthermore, tests of effort-based choice have identified compounds that are particularly useful for stimulating high-effort work output and reversing the deficits induced by tetrabenazine and cytokines. These studies indicate that drugs that act by facilitating dopamine transmission, as well as adenosine $A_{2 A}$ antagonists, are relatively effective at reversing effort-related impairments. Studies of effort-based choice may lead to the identification of drug targets that could be useful for treating motivational treatments that are resistant to commonly used antidepressants such as serotonin transport inhibitors.

\section{Introduction: Motivational Processes and Psychopharmacology}

Address correspondence to: Dr. John D. Salamone, Department of Psychological Sciences, Division of Behavioral Neuroscience, University of Connecticut, Storrs, CT 06269-1020. E-mail: john. salamone@uconn.edu

Much of the work described in this review was supported by grants to J.D.S. from the National Institutes of Health National Institute of Mental Health, the UCONN Research Foundation, and Shire and Prexa, and to M.C. from MEC (PSI2015-68497-R).

https://doi.org/10.1124/pr.117.015107. 
stressful or aversive conditions; Salamone, 1992, 2010). In addition, there are activational aspects that refer to the fact that the initiation and maintenance of motivated behavior can be characterized by high levels of activity, vigor, and persistence in work output (Salamone, 1992, 2010; Salamone et al., 2017). The distinction between directional and activational aspects of motivation has been an important feature of the literature in psychology for many decades (Duffy, 1963; Cofer and Appley, 1964; Salamone, 1987, 1988; see review by Salamone et al., 2017), and activational aspects of motivation are seen as critical for survival because they enable organisms to exert the effort necessary for overcoming the work-related constraints that separate them from significant stimuli.

Studies of behavioral activation are not only relevant for investigating the neurochemical or physiologic basis of normal motivation. They also are important for understanding aspects of psychopathology. Although fatigue is sometimes difficult to define, it has been described as the most common psychiatric symptom in general medicine (Stahl, 2002). Terms such as fatigue, anergia, apathy, psychomotor retardation, amotivation, and negative symptoms are used to describe a lack of behavioral activation that can be seen across a host of psychiatric and neurologic disorders, as well as various medical conditions, including inflammation (Stahl, 2002; Dantzer et al., 2014; Salamone et al., 2016a,c). These motivational symptoms are difficult to treat with conventional medications such as serotonin (5-HT) selective uptake inhibitors (SSRIs) (Stahl, 2002; Cooper et al., 2014; Fava et al., 2014; Rothschild et al., 2014), and thus present an important unmet need. For these reasons, the development of animal models of effort-related motivational dysfunctions could serve to enhance our understanding of the neurochemical basis of motivational pathologies and may foster the development of drug treatments for motivational symptoms.

Over the past few decades, an emerging area of research has focused on effort-based decision making (Salamone et al., 1991, 1994a, 1997, 2007, 2016a,b,c; Walton et al., 2003; Floresco et al., 2008; Mai et al., 2012; Salamone and Correa, 2012; Winstanley and Floresco, 2016). In a complex environment that offers potential access to many different motivational stimuli, and several possible paths to obtain them, organisms must make decisions about which conditions to seek or pursue. Frequently, this involves making choices based upon cost/benefit analyses. Thus, the possible gains represented by various aspects of motivational value (e.g., the quantity or quality of a reward, or its relative preference) must be weighed against the instrumental response costs involved in obtaining access to the motivational stimuli in question. These instrumental response costs are essentially opportunity costs presented by the time and effort it takes to engage in a particular activity coupled with the fact that doing one thing often precludes being able to do something else. Effort-based costs involve features of behavior related to energy expenditure, task difficulty, and repetition of responses over time. Whether an animal is foraging in the wild (see research on optimal foraging theory; Krebs, 1977) or being tested in the laboratory (Van den Bos et al., 2006), these costs and benefits must be reconciled and translated into a coherent pattern of behavior to promote survival.

Much has been learned about the pharmacology of effort-related choice (Salamone and Correa, 2002, 2012; Bailey et al., 2016; Salamone et al., 2016a,b,c; Winstanley and Floresco, 2016), and recently, animal procedures have been developed that represent formal models that can be used to promote the development of drug treatments for motivational dysfunction (Simpson et al., 2012; Nunes et al., 2013a,b; Randall et al., 2015a,b; Sommer et al., 2014; Yohn et al., 2015a,b, 2016a,c,d,e). This line of inquiry is validated by human studies showing that alterations in effort-based decision making are associated with depression (Treadway et al., 2012; Yang et al., 2014, 2016), schizophrenia (Gold et al., 2013), and Parkinson's disease (Chong et al., 2015). This work will review recent research on the pharmacology of effortbased decision making, with the main focus being on animal research, and will describe how this line of research has illuminated features of the neurobiology of motivational dysfunction and may lead to the development of novel drug treatments.

\section{Neural Circuits and Transmitters Mediating Effort-Based Choice: Mesolimbic Dopamine}

Basic research with rodents has demonstrated that effort-based decision making is regulated by a distributed forebrain circuity that involves many brain areas and neurotransmitters, with mesolimbic dopamine (DA) playing a major role (Salamone et al., 2016a,b,c). Typically, effort-based decision making is assessed using tasks that offer animals a choice between a relatively preferred reinforcer that can only be obtained by a high exertion of effort versus a lower effort/lower value option (Fig. 1). Some tasks use operant behavior methods to study response allocation under conditions in which working for a preferred food by lever pressing is the high-effort option and simply approaching and consuming a less preferred laboratory chow is the low-effort option. Using this type of procedure, several studies have employed tasks in which the lever-pressing option is a type of fixed ratio (FR) or progressive ratio (PROG) schedule that is reinforced by relatively preferred high carbohydrate operant pellets, and the low-effort/low-preference alternative is standard laboratory chow that is freely available in the chamber. (Salamone et al., 1991; Randall et al., 2012; Sommer et al., 2014; Fig. 1, left). With the concurrent FR5/chow-feeding choice task (Salamone et al., 1991; Yohn et al., 2016a,b,c,d,e), both options are available concurrently, and animals are free to allocate 


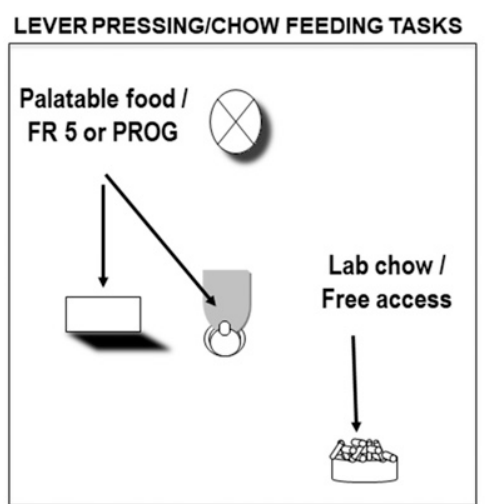
CHOICE: Lever press for preferred high-carbohydrate pellets vs. approach and consume less preferred lab chow

T-MAZE BARRIER CHOICE TASK
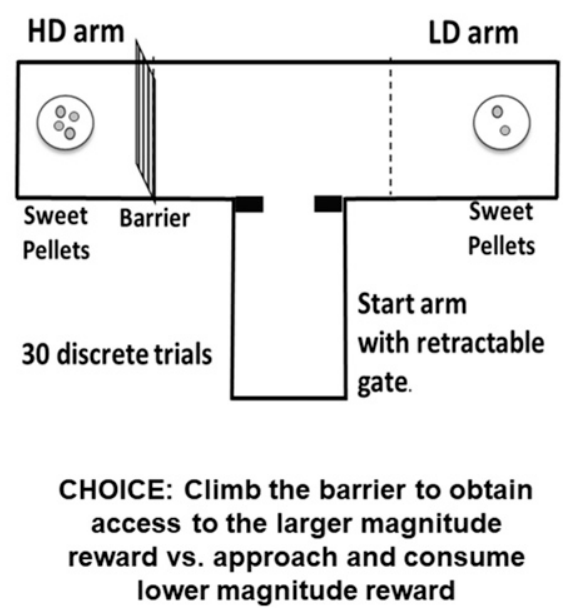

Fig. 1. Effort-related choice tasks conducted in rodent operant boxes and mazes (see cited references in text for details). Left: The concurrent leverpressing/chow-feeding choice tasks give animals the option of lever pressing on a fixed or progressive ratio schedule to obtain access to preferred highcarbohydrate pellets versus approaching and consuming freely available chow. Right: The T-maze barrier choice task presents trials that allow animals to select one arm that requires them to climb a vertical barrier to obtain a large magnitude of reinforcement versus the other arm, which has no barrier and a lower magnitude of reinforcement.

their behavior across the different choices. In contrast, with the most commonly used version of the PROG/ chow-feeding choice procedure (Randall et al., 2012, $2015 \mathrm{a}, \mathrm{b})$, if an animal fails to obtain a reinforcer within a 2-minute period, the lever-pressing option will end, and the only option is to approach and consume chow. A discrete trial T-maze barrier choice task also has been developed (Salamone et al., 1994; Pardo et al., 2012; Yohn et al., 2015a,b; Fig. 1, right), and with this procedure rodents have a choice across multiple trials between one arm that contains a high magnitude of food and the other arm that contains a low density of food (e.g., four pellets versus two pellets). An effort-related challenge is provided under some conditions, in which the high density of reinforcement can only be obtained by climbing a vertical barrier. Furthermore, there are effortdiscounting procedures that have been used, which employ either different FR lever-pressing requirements or a T-maze with a barrier to control the effort component (Floresco et al., 2008; Bardgett et al., 2009).

Considerable evidence implicates brain DA systems, particularly mesolimbic DA, in regulating behavioral activation, the exertion of effort, and effort-based decision making. Motivational conditions such as periodic presentation of small amounts of food (e.g., single $45 \mathrm{mg}$ food pellets) to food-restricted rats can generate intense activities such as polydipsia, wheel running, and high levels of motor activity, and evidence indicates that DA antagonism and depletion of mesolimbic DA blunt these activities (Robbins and Koob, 1980; Wallace et al., 1983; Salamone, 1986, 1988; McCullough and Salamone, 1992). One way of controlling the work requirement of an operant schedule is to vary the ratio requirement (i.e., the number of lever presses required for reinforcement). Several studies have shown that the effects of DA antagonism and nucleus accumbens DA depletions interact with the ratio requirements of an operant procedure, and that impairments are greater on schedules with a larger ratio requirement (Aberman and Salamone, 1999; Caul and Brindle, 2001; Salamone et al., 2001; Ishiwari et al., 2004). If ratio requirements are attached to the time interval requirements of an operant schedule (i.e., a variable interval schedule with a ratio requirement attached in tandem), the effects of nucleus accumbens DA depletions interact with the ratio requirements of the schedule, but not the time interval requirement (Correa et al., 2002; Mingote et al., 2005). This observation is consistent with the results of studies showing that interference with accumbens DA transmission did not affect delay discounting (Winstanley et al., 2005; Li et al., 2015) or progressive interval lever pressing (Wakabayashi et al., 2004).

Across a wide variety of tasks, administration of low doses of DA antagonists and accumbens DA depletions has been shown to alter effort-based decision making, producing a low-effort bias that shifts animals away from the high-effort option and toward the low-effort choice. In studies that have used the concurrent FR5/chow-feeding choice procedure, a low-effort bias can be reliably induced by systemic administration of low doses of DA D1 or D2 family antagonists such as SCH23390, ecopipam, haloperidol, raclopride, and eticlopride (Salamone et al., 1991, 2002; Cousins and Salamone, 1994; Koch et al., 2000; Farrar et al., 2007; Sink et al., 2008), as well as by intraaccumbens DA antagonism (Nowend et al., 2001; Farrar et al., 2010) and accumbens DA depletions produced by local injections of 6-hydroxydopamine (Salamone et al., 1991; Cousins et al., 1993; Sokolowski and Salamone, 1998). This shift in choice is marked by a substantial reduction in lever pressing and a concomitant increase 
in chow intake. PROG/chow-feeding choice performance also has been used to assess the effort-related effects of DA antagonism. Administration of DA D1 or D2 family antagonists reduced PROG lever pressing, but, on this task, which generates relatively high baseline levels of chow intake, DA antagonism did not suppress intake of the concurrently available chow, in fact tending to increase it still further (Randall et al., 2012, 2015a). Several papers have reported that T-maze barrier choice performance also is affected by DA antagonism and depletion; these manipulations reduce climbing of the maze arm with the barrier (the high e-effort option) and increase selection of the arm with no barrier and the lower magnitude of reward (Salamone et al., 1994; Cousins et al., 1996; Mott et al., 2009; Pardo et al., 2012; Yohn et al., 2015a). Furthermore, tests of effort discounting using both lever-pressing and maze procedures have shown that DA D1 and D2 antagonism shifted choice in the direction of a low-effort preference (Floresco et al., 2008; Bardgett et al., 2009; Hosking et al., 2015).

Recent studies have involved administration of the pharmacological DA-depleting agent tetrabenazine. Tetrabenazine is a potent and reversible inhibitor of the vesicular monoamine transporter type-2, and blockade of this protein inhibits vesicular storage of monoamines, thereby leading to neurotransmitter depletion. At low doses, tetrabenazine is relatively selective at reducing levels of DA compared with norepinephrine (NE) and 5-HT (Pettibone et al., 1984; Tanra et al., 1995). Low doses of tetrabenazine that reduced extracellular DA in nucleus accumbens by $75 \%$ and altered DA-related signal transduction as measured by alterations in phosphorylated DARPP-32 (DA and cAMP-related phophoprotein, $32 \mathrm{kDa}$ ) were shown to shift choice behavior and induce a low-effort bias in rats tested on the FR5/chowfeeding choice task (Nunes et al., 2013b). The shift from lever pressing to chow intake was seen after local injections of tetrabenazine into nucleus accumbens core, but not into overlying dorsomedial neostriatum (Nunes et al., 2013b). Tetrabenazine also alters effort-based choice in rats tested on a concurrent FR7/choice procedure that used different sucrose concentrations as the reinforcer (Pardo et al., 2015), the PROG/chow-feeding choice task (Randall et al., 2015a), and the T-maze barrier choice task (Yohn et al., 2015a,b).

\section{Behavioral Effects of Dopaminergic Manipulations on Effort-Related Tasks Are Not Due to Broad or General Changes in Reward, Temporal Processing, or Motor Incapacity}

As described above, across diverse tasks conducted in multiple laboratories, using a number of different pharmacological and neurotoxic tools, it has been shown that interference with DA transmission shifted choice behavior from task components that require a high degree of effort to those that involve a lower exertion of effort. Of course, to interpret these effects as being dependent upon the effort-related features of the task, it is important to demonstrate that they are not due to other potential manifestations of reduced DA transmission. For example, whenever one studies any aspect of the behavioral functions of DA, a commonplace comment may be that a global or general deficit in reward underlies the effect being reported. The DA hypothesis of reward is a ubiquitous feature of the scientific literature, as well as popular media, the internet, and film. Yet, despite the almost automatic tendency of some to explain virtually any aspect of DA function as somehow being dependent on reward, there are critical theoretical and empirical problems with this, many of which have been reviewed in detail elsewhere (Salamone et al., 1997, 2007; Salamone and Correa, 2002, 2012; Floresco, 2015; Nicola, 2016). First and foremost, the term reward has no consistent scientific meaning (Salamone et al., 2005; Salamone and Correa, 2012), and, depending upon the paper, or even the paragraph, this term is used variously to refer to subjective pleasure or hedonic reactivity, appetite, preference, and even reinforcement learning. Given the slippery and imprecise nature of this term, it is wholly inadequate to attribute specific effects in experiments simply to reward without any qualification or explication. Nevertheless, it is useful, even critical, to determine whether impairments in specific aspects of appetitive motivation such as reinforcer preference, appetite, or hedonic reactivity, as well as other factors such as delay of reinforcement or motoric capacity, underlie the behavioral effects of dopaminergic manipulations on effort-related performance.

The most common reinforcer used in studies of effortbased choice is food, and an enormous body of evidence has demonstrated that the dopaminergic conditions that produce a low-effort bias in rodents do not alter food intake, preference for the different foods used, or discrimination of reinforcer magnitude, and do not reduce sucrose preference or hedonic reactivity. Although the concurrent FR5/ and PROG/chow-feeding choice procedures involve lever pressing for one type of food (high-carbohydrate pellets) versus approaching and consuming a different food (standard laboratory chow), free feeding preference studies have shown that the conditions that produce the shift in choice behavior (low doses of DA antagonists, DA depletions) do not reduce total food intake or the preference for highcarbohydrate pellets over chow (Salamone et al., 1991; Koch et al., 2000; Nunes et al., 2013b). With animals tested in the T-maze barrier task, DA antagonism and depletion shift arm choice away from the arm with the barrier that has the high density of food reinforcement; however, these manipulations have no effect on choice of the high-reinforcement versus low-reinforcement arm when no barrier is present (Salamone et al., 1994; Yohn et al., 2015a,b). Although tetrabenazine was shown to decrease lever pressing for a high concentration of sucrose and increase intake of a concurrently available 
lower concentration, it did not alter intake of or preference for the different concentrations of sucrose used (Correa et al., 2016). Moreover, tetrabenazine did not alter markers of hedonic reactivity to sucrose (Correa et al., 2016), which is consistent with the large body of research from Berridge, Robinson, and colleagues indicating that interference with DA transmission does not alter hedonic reactivity to sucrose (Berridge, 2007; Berridge and Robinson, 1998, 2003). Thus, dopaminergic manipulations that affect effort-based choice are not altering choice based upon the quality or quantity of food; they are altering the choice of instrumental behavior that the animal uses to obtain food, and altering it in such a way as to bias the animal toward the lower effort response. Furthermore, studies have shown repeatedly that the effects of interference with DA transmission on effort-based choice do not resemble the effects of reinforcer devaluation by prefeeding (Salamone et al., 1991; Randall et al., 2012; Pardo et al., 2015) or appetite-suppressant drugs (Salamone et al., 2002; Sink et al., 2008; Randall et al., 2012, 2015a). Taken together, these results demonstrate that the induction of a low-effort bias in animals treated with DA antagonists or depleting agents is not due to impairments in the primary or unconditioned reinforcing characteristics of food (Kelley et al., 2005; Salamone et al., 2007, 2016a,b,c).

As noted above, choosing to lever press for one type of food versus approaching and consuming another, or selecting one maze arm versus another, naturally involves a cost/benefit analysis. There are response costs related to effort and time that are involved in any action, and thus opportunity costs involving effort and time when one chooses one action over another. Because lever pressing on a ratio schedule or running in a maze and climbing a barrier both involve time, it is useful to consider the potential role of intermittence or delay of reinforcement as a possible mediating variable in studies of effort-based choice. A described above, there is evidence that intermittence of reinforcement per se is not an important determinant of the effects of accumbens DA depletions or antagonism on instrumental response output (Correa et al., 2002; Wakabayashi et al., 2004; Mingote et al., 2005). Moreover, studies have reported that delay discounting is not affected by accumbens DA depletions (Winstanley et al., 2005) or intra-accumbens DA antagonism ( $\mathrm{Li}$ et al., 2015). Furthermore, Floresco et al. (2008) developed an equivalent delay procedure that was designed to control for the effects of the delays involved in ratio lever pressing on delay discounting performance. They observed that the DA antagonist flupenthixol produced a low-effort bias in tests of ratio discounting even when controlling for response-related delays (Floresco et al., 2008). Thus, it does not appear that time delays in themselves can provide the sole explanation for the pattern of effects induced by DA antagonism or depletion in studies of effort-based choice. Nevertheless, it is possible that time becomes more relevant when sustained effort over very large units of time is required. For example, although animals with accumbens DA depletions can emit normal numbers of responses when ratio requirements are low, they show a catastrophic loss of responding when very large ratios (e.g., FR300) are required in the absence of primary reinforcement, even if the overall magnitude of reinforcement is the same across ratio schedules (Salamone et al., 2001). In that case, these results suggest that the deficit induced by DA depletion is not simply one of reducing the total number of responses, but instead appears to interact with how the response requirement is organized.

It is generally recognized that DA systems are involved in aspects of motor function, so it is natural to ask whether the effects of dopaminergic manipulations on effort-based choice are simply due to a deficit in motor capacity, or an absolute ceiling on the number of times an animal can press a lever or climb a barrier. On the one hand, there is evidence demonstrating that the changes in effort-related performance that follow DA depletions do not depend simply on an impairment in the absolute number of responses that can be emitted by the animal. Cousins and Salamone (1994) reported that in rats with moderate depletions of accumbens DA depletions, deficits were seen in FR5 responding when the animals were tested on the concurrent FR5/chowfeeding choice task (i.e., when they had an alternative food source available), but the same animals did not show significant reductions in FR5 lever pressing when no other food source was available, and the only way to obtain food was through lever pressing. Mice tested on the T-maze barrier choice after injections of haloperidol showed no deficit in arm selection when both arms had a barrier (Pardo et al., 2012). Similarly, DA-depleted rats tested on the T-maze barrier choice task showed deficits in barrier climbing when the no-barrier arm contained some food, but did not show significant reductions in barrier climbing when that was the only way to obtain food (Cousins et al., 1996; Yohn et al., 2015b). Furthermore, analyses of latency data in animals tested on the T-maze task have shown that run latency is not a statistical mediator of the effect of dopaminergic manipulations on arm choice (Yohn et al., 2015a,b). Thus, it appears that the animals with impaired DA transmission are capable of responding, but they are selecting the path to food reinforcement that involves less effort.

\section{What Fundamental Processes Underlie the Low-Effort Bias Induced by Interference with Dopamine Transmission?}

As described above, an enormous body of evidence demonstrates that one can induce profound alterations in the allocation of instrumental responses in animals responding on choice tasks by interfering with DA transmission, either by low doses of DA antagonists, 
pharmacological depletion of DA, or local DA antagonism or depletion in nucleus accumbens. By a process of elimination, these behavioral effects are not easily attributable to a reduction in primary food motivation, appetite, reinforcer preference, reference memory, delay of reinforcement, or a severe motor impairment that renders the organism incapable of responding. In that case, it is worthwhile to consider what the fundamental neurobehavioral processes are that mediate the effects of dopaminergic manipulations on effort-based choice. As alluded to in a previous paper, the motivational functions of mesolimbic DA appear to be somewhat mysterious (Salamone and Correa, 2012), and there continues to be debate about the specific role that DA systems play in aspects of motivation (Nicola, 2016). The section below will provide a brief theoretical perspective on concepts that help to explain how some of the diverse motivational functions of mesolimbic DA are particularly relevant for understanding the impact of dopaminergic manipulations on effort-related choice.

Perhaps the most important contribution of behavioral sciences to neuroscience is the idea that complex psychologic processes such as motivation, cognition, motor function, and emotion are not unitary in nature, but in fact can be deconstructed into dissociable parts by manipulating the nervous system (Salamone and Correa, 2002; Berridge and Robinson, 2003; Salamone et al., 2007). Furthermore, it is necessary to recognize that some of these dissociated component functions fall into areas of overlap between traditional constructs (Salamone and Correa, 2017). For example, the behavioral activation functions of mesolimbic DA are not strictly motivational or motoric in nature because there is actually a fundamental overlap between activational aspects of motivation and movement control that has been recognized and discussed for decades (Mogenson et al., 1980; Salamone, 1992; Salamone and Correa, 2002, 2012; Salamone et al., 2017). Thus, it is critical to consider not only what is impaired by interference with DA transmission but also what is intact, and to decipher the meaning behind this pattern of results.

Animals with impaired mesolimbic DA transmission remain directed toward the acquisition and consumption of food reinforcement (Koob et al., 1978; Salamone et al., 1991, 1993, 1994; Kelley et al., 2005; Nunes et al., 2013b; Yohn et al., 2015b), and, when tested on instrumental tasks that involve minimal work, they show little or no impairment (McCullough et al., 1993; Salamone et al., 2001, 2017; Correa et al., 2002; Ishiwari et al., 2004; Mingote et al., 2005). However, motivational stimuli have several distinct behavioral effects, and it appears that interference with DA transmission can impair some of them, despite leaving aspects of primary or unconditioned reinforcement intact. Motivational stimuli that act as positive reinforcers can have behaviorally activating effects and can support the instigation and maintenance of highly vigorous instrumental behaviors.
Associative processes that underlie primary reinforcement can be intertwined with Pavlovian processes, and conditioned stimuli allow organisms to predict and anticipate reinforcement, which is necessary for promoting and sustaining instrumental behavior.

The behaviorally selective effects of DA antagonism or depletion on specific aspects of motivational processes can lead to interesting dissociations. Systemic administration of haloperidol can dramatically reduce the locomotor activation induced by scheduled food presentation, while leaving performance of a very simple instrumental response intact (Salamone, 1986, 1988). Low doses of DA antagonists and accumbens DA depletions can leave a relatively simple instrumental behavior intact (e.g., FR1 lever pressing), but, with larger and larger ratio requirements (FR5 up to FR300), a clear and ultimately catastrophic impairment emerges (McCullough et al., 1993; Aberman and Salamone, 1999; Salamone et al., 2001, 2017; Ishiwari et al., 2004). In behavioral economic terms, interference with DA transmission increases elasticity of demand for food reinforcement and reduces the willingness to pay for food reinforcement while leaving preference-related aspects of value intact (Aberman and Salamone, 1999; Salamone et al., 2009, 2016a,c, 2017). Furthermore, considerable evidence indicates that accumbens DA regulates Pavlovian approach behavior and the activating effects of Pavlovianconditioned stimuli on instrumental behavior (Wyvell and Berridge, 2000; Parkinson et al., 2002; Lex and Hauber, 2008).

Taking all this together, it is reasonable to suggest that many of the behaviors that are highly sensitive to interference with mesolimbic DA transmission are vigorous instrumental activities that are instigated or sustained by conditioned stimuli (Salamone and Correa, 2012). This view of DA function resonates with classic ideas about the role of conditioned stimuli in motivated behavior. Cofer and Appley (1964) suggested that there was an anticipation-invigoration mechanism, which is turned on by conditioned stimuli and then serves to activate or invigorate instrumental behavior. Because pursuit of reinforcement in the laboratory or the wild often requires considerable response vigor, and actions must be instigated in the absence of primary reinforcement, a major function of mesolimbic DA involves bridging the psychologic distance that separates organisms from motivationally significant stimuli (Salamone and Correa, 2012). In the context of effort-related decision-making tasks, in which behavior is supported by primary reinforcement but also by discrete cues or contextual stimuli, the net result of interfering with accumbens DA transmission is to reduce the tendency to work vigorously for food reinforcement. But given that these animals are still directed toward the acquisition and consumption of food, their behavior becomes redirected and they choose the lower-effort path to food procurement. 
It also appears that these effects of impaired DA transmission are related to decision making based upon physical effort as opposed to other types of factors. Hosking et al. (2015) reported that DA antagonism impaired discounting based upon physical effort, but not cognitive effort. Although local injection of DA D2 antagonists into nucleus accumbens core has been shown to alter effort-related decision making (Nowend et al., 2001; Farrar et al., 2010), the same manipulation did not affect decision making based upon risk (Stopper et al., 2013). A recent study reported on the effects of the DA-depleting agent tetrabenazine on a T-maze choice task in which mice could choose between running in a running wheel versus approaching and consuming sucrose pellets. Tetrabenazine shifted choice behavior, decreasing selection of running wheel activity but actually increasing consumption of sucrose (Correa et al., 2016). This finding illustrates that under some circumstances interfering with DA transmission can actually increase the relative reinforcing value of sucrose, and also serves to underscore the role of physical effort as a factor in determining sensitivity to dopaminergic impairments.

Although this study is focused on the pharmacology of effort-based choice, it is important to consider the relation between the behavioral pharmacology findings reviewed above and what is known about the activity of DA neurons in the context of instrumental conditioning. Studies employing electrophysiology and neurochemistry methods demonstrate that DA neuron activity is not simply tied to the delivery of primary positive reinforcers across a broad range of conditions (Marinelli and McCutcheon, 2014; Salamone et al., 2016a). Rather, it appears that the phasic DA signaling responses in accumbens as measured in animal experiments are context dependent, they vary across fast and slow timescales, and what is being responded to depends upon the details of the behavioral procedures being used. A substantial literature demonstrates that fast phasic DA neuron responses represent a reward prediction error, which could be related to the expected utility of rewards (Stauffer et al., 2016). However, the specific relation between reward prediction error signals and exertion of effort remains uncertain. For example, knockout of ventral tegmental $N$-methyl-D-aspartate receptors, which dramatically reduces phasic DA signaling, was reported to have no effect on PROG responding (Zweifel et al., 2009). There also is evidence that prolonged DA signaling (i.e., ramps) in response to stimuli that are distant in time and space from the reinforcer is associated with a sustained motivational drive that maintains instrumental behavior during maze learning (Howe et al., 2013). Hamid et al. (2016) studied DA signaling as measured by fast cyclic voltammetry responses in rats that were behaving a flexible decisionmaking task, which had distinct phases that ultimately led to reinforcement. They observed that phasic DA responses increased in magnitude as animals progressively passed through the task phases and moved toward the increasing likelihood of reinforcement at the end. These DA signals were correlated with important aspects of behavioral output, such as latency to instigate the behavioral response. These DA-related signals increased as the animals progressed through the phases of the task even when reward was predicted, and thus did not represent a reward prediction error response. This led Hamid et al. (2016) to suggest that mesolimbic DA helps to translate estimates of reinforcer availability into decisions to work for reinforcers, and that mesolimbic DA release could be providing a motivational signal regulating behavioral activation and the decision of whether or not to engage in effortful activity while working for rewards. Overall, several studies have reported an association between instrumental response output and pre- or postsynaptic markers of DA-related signaling (Sokolowski et al., 1998; Segovia et al., 2011, 2012; Howe et al., 2013; Saddoris et al., 2015; Hamid et al., 2016; Ko and Wanat, 2016; Wood et al., 2017). Furthermore, selective chemogenetic activation of mesolimbic DA neurons was recently reported to increase responding for sucrose in rats responding on a PROG schedule (Boekhoudt et al., 2018). This effect was characterized by increased initiation of bouts of instrumental behavior and was not seen after activation of nigrostriatal DA neurons. Optogenetic inhibition of ventral tegmental area DA neurons suppressed the initiation and the maintenance of effortful operant responding on FR8 and PROG schedules (FischbachWeiss et al., 2018). Taken together, these studies provide additional evidence of the importance of DA neuron activity in the regulation of response vigor and work output.

\section{Neural Circuits and Transmitters Mediating Effort-Based Choice: Adenosine, GABA, and Nondopaminergic Components of the Circuit}

Despite the clear importance of DA in regulating effort-based choice, it is nevertheless evident that no single neurotransmitter or brain area participates in a complex behavioral process on its own. Thus, it is important to review the nondopaminergic components of the neural circuitry that has been implicated in effortrelated decision making. Over the last several years, a number of laboratories have begun to characterize the role that various brain structures and neurotransmitters play in effort-related choice behavior. Multiple studies have shown that anterior cingulate/prefrontal cortex is an important part of the circuitry regulating effort-based choice. Large lesions of prefrontal cortex produce a low-effort bias in rats tested on the T-maze choice task (Walton et al., 2002), and subsequent work showed that these effects were largely attributable to lesions targeting anterior cingulate cortex (Walton et al., 2003). Schweimer and Hauber (2006) reported that depletions of anterior cingulate DA by injections of 
6-hydroxydopamine also were able to shift T-maze barrier choice performance. Hart et al. (2017) found that excitotoxic lesions of anterior cingulate cortex decreased PROG lever pressing for sucrose pellets while leaving intake of concurrently available chow unaffected. The effects of anterior cingulate lesions in this study were not mediated by decreased appetite, a change in food preference, or a failure to update reinforcement value. Floresco and Ghods-Sharifi (2007) found that the basolateral amygdala and its connections with the anterior cingulate cortex form part of a serial circuitry regulating effort-related decision making.

Considerable evidence indicates that DA interacts with the neuromodulator adenosine in striatal areas, including neostriatum and nucleus accumbens, and that drugs that act on adenosine receptors can exert substantial behavioral effects. Caffeine and other methylxanthines such as theophylline and theobromine act as minor stimulants via their actions as nonselective antagonists of adenosine receptors (Ferré et al., 2008; Randall et al., 2011; Pardo et al., 2013; López-Cruz et al., 2014, 2016). The $\mathrm{A}_{1}$ and $\mathrm{A}_{2 \mathrm{~A}}$ subtypes are the major adenosine receptors in the brain, and nucleus accumbens and neostriatum have a very high expression of adenosine $\mathrm{A}_{2 \mathrm{~A}}$ receptors (Schiffmann et al., 1991; DeMet and Chicz-DeMet, 2002; Ferré et al., 2004). Several studies have reported that there are cellular interactions of DA D2 and adenosine $\mathrm{A}_{2 \mathrm{~A}}$ receptors that are colocalized on the same striatal and accumbens medium spiny neurons, which include the ability to form heteromeric complexes and convergence onto the same cAMP/protein kinase A signal transduction cascade (Schiffmann et al., 1991; Ferré, 1997; Svenningsson et al., 1999; Fuxe et al., 2003). Adenosine $\mathrm{A}_{2 \mathrm{~A}}$ receptor antagonists have been investigated and developed as potential antiparkinsonian agents (Ferré et al., 1997, 2001; Morelli and Pinna, 2001; Correa et al., 2004; Pinna et al., 2005; Salamone et al., 2008a,b), and istradefylline is currently used in Japan for the treatment of Parkinson's disease (Kondo et al., 2015). Furthermore, drugs that stimulate or inhibit adenosine $\mathrm{A}_{2 \mathrm{~A}}$ receptors induce substantial effects on operant behavior and effort-related choice. Intra-accumbens injections of the adenosine $\mathrm{A}_{2 \mathrm{~A}}$ agonist CGS 21680 attenuated lever pressing in rats responding on a tandem VI 60 second/FR10 schedule, but did not impair performance on a standard VI 60 second schedule (Mingote et al., 2008). Infusion of CGS 21680 directly into nucleus accumbens shifted effort-related choice, decreasing FR5 lever pressing and increasing chow intake (Font et al., 2008), whereas control infusions into overlying dorsomedial neostriatum were ineffective. In general, stimulation of adenosine $\mathrm{A}_{2 \mathrm{~A}}$ receptors in nucleus accumbens appears to induce similar effects to those produced by accumbens DA depletions or antagonism.

Several different adenosine $\mathrm{A}_{2 \mathrm{~A}}$ receptor antagonists, including MSX-3, MSX-4, Lu AA47070, and istradefylline, have been shown to reverse the low-effort bias induced by systemically administered DA D2 antagonists in rats tested on the FR5/chow-feeding choice task (Farrar et al., 2007; Salamone et al., 2009; Worden et al., 2009; Nunes et al., 2010; Collins et al., 2012; Santerre et al., 2012). Intra-accumbens injections of MSX-3 reversed the effects of intra-accumbens injections of the D2 antagonist eticlopride in rats responding on the FR5/chow concurrent choice task (Farrar et al., 2010). Antagonism of adenosine $\mathrm{A}_{2 \mathrm{~A}}$ receptors also reverses the effects of D2 antagonism in rats (Mott et al., 2009) and mice (Pardo et al., 2012) tested on the T-maze barrier choice task, and adenosine $\mathrm{A}_{2 \mathrm{~A}}$ receptor knockout mice are resistant to the effects of haloperidol on selection of the barrier arm of the T-maze (Pardo et al., 2012). These effects of adenosine $A_{2 A}$ receptor antagonists on effort-related choice are subtype specific, as several papers have reported that blockade of adenosine $A_{1}$ receptors does not attenuate the effects of either DA D1 or D2 antagonists (Mott et al., 2009; Salamone et al., 2009; Nunes et al., 2010; Pardo et al., 2012). Studies using signal transduction markers of DA D2 transmission, such as cFos and phosphorylated DARPP-32, indicate that adenosine $\mathrm{A}_{2 \mathrm{~A}}$ receptor antagonists are so effective in reversing the effort-related effects of D2 antagonists because $\mathrm{A}_{2 \mathrm{~A}}$ blockade directly attenuates the signal transduction effects of D2 antagonism in medium spiny neurons that colocalize both receptors (Farrar et al., 2010; Santerre et al., 2012).

Nucleus accumbens core medium spiny neurons that colocalize DA D2 and adenosine $\mathrm{A}_{2 \mathrm{~A}}$ receptors use GABA as their neurotransmitter and project to lateral ventral pallidum (Farrar et al., 2008; Mingote et al., 2008). GABA release in lateral ventral pallidum is increased by blockade of accumbens core $\mathrm{D} 2$ receptors (Salamone et al., 2010), and also by stimulation of accumbens adenosine $A_{2 A}$ receptors (Mingote et al., 2008). Consistent with these findings, injections of the $\mathrm{GABA}_{\mathrm{A}}$ receptor agonist muscimol into lateral ventral pallidum produced a low-effort bias in rats tested on the FR5/chow-feeding choice task (Farrar et al., 2008). Moreover, an experiment using disconnection methods demonstrated that unilateral injections of the adenosine $\mathrm{A}_{2 \mathrm{~A}}$ agonist CGS21680 into nucleus accumbens on one side of the brain, combined with contralateral injections of muscimol into lateral ventral pallidum, produced a strong impairment in high-effort instrumental responding that was not seen after various control procedures (Mingote et al., 2008). These results indicate that nucleus accumbens and lateral ventral pallidum form part of a serial circuit-mediating effort-based choice. Interestingly, other disconnection experiments have been performed on other parts of the forebrain circuitry, and these studies indicate that there is a series of connections involving basolateral amygdala, anterior cingulate cortex, nucleus accumbens, and ventral pallidum, which together participate in the regulation of effort-related decision 
making (Fig. 2). Several studies have identified that nucleus accumbens core as being a critical striatal component of this circuitry (Sokolowski et al., 1998; Nowend et al., 2001; Font et al., 2008; Mingote et al., 2008; Hauber and Sommer, 2009; Farrar et al., 2010; Ghods-Sharifi and Floresco, 2010; Randall et al., 2012; Nunes et al., 2013b), although there is some evidence that nucleus accumbens shell also participates (Nowend et al., 2001). To date, evidence is mixed on the role of DA in medial neostriatum (Cousins et al., 1993; Farrar et al., 2010), although this area appears to be important for DA/5-HT interactions regulating response vigor and exertion of effort (Bailey et al., 2018).

Several other manipulations that affect brain function have been identified as producing effects on effort-based choice. Injections of the muscarinic acetylcholine agonist pilocarpine directly into nucleus accumbens shifted effort-related choice in rats tested on the FR5/chowfeeding choice task, and these actions were reversed by coadministration of scopolamine (Nunes et al., 2013a). Genetic deletion of the neuronal calcium sensor-1, which reduces accumbens DA transmission, made mice less willing to work for food, but left food preference, responding for conditioned reinforcement, and the ability to represent changes in reward value intact $(\mathrm{Ng}$ et al., 2016). Inactivation of the lateral hypothalamus produced a low-effort bias as marked by a reduction in barrier climbing in the T-maze (Karimi et al., 2017). Glycine acts as both an inhibitory neurotransmitter and a co-agonist at the $N$-methyl-D-aspartate receptor, and recent studies indicate that the glycine uptake inhibitor bitopertin can reverse the effort-related effects of haloperidol in rats tested on the FR5/chow-feeding and T-maze barrier choice tasks (Yohn et al., 2017a). The nutritional supplement curcumin, when ingested orally or injected directly into the ventricles of the brain, was able to reverse the effects of tetrabenazine in rats tested on the concurrent FR5/chow-feeding choice task (Yohn et al., 2017b).

\section{Clinical Implications: Targeting Drugs for the Potential Treatment of Effort-Based Dysfunctions}

As described above, behavioral activation and effortrelated processes are critically important aspects of normal motivation. In addition, the clinical literature demonstrates that deficits in these processes can be a disabling feature of human psychopathology. Terms such as fatigue, apathy, anergia, psychomotor retardation, amotivation, and negative symptoms are employed to describe psychiatric symptoms characterized by a lack of behavioral activation that can be seen across several different disorders, including depression and schizophrenia (Salamone et al., 2006, 2015; Treadway and Zald, 2011; Barch et al., 2014; Dantzer et al., 2014; Whitton et al., 2015; Le Heron et al., 2017; De Doncker et al., 2018). These motivational symptoms are highly debilitating in depressed people (Tylee et al., 1999), and factor analysis studies showed that there is an anergia/fatigue factor that is correlated with the overall severity of depression (Gullion and Rush, 1998). Patients with Parkinson's disease also show motivational dysfunctions such as fatigue and apathy (Friedman

\section{FOREBRAIN CIRCUITRY INVOLVED IN EFFORT-RELATED FUNCTIONS}

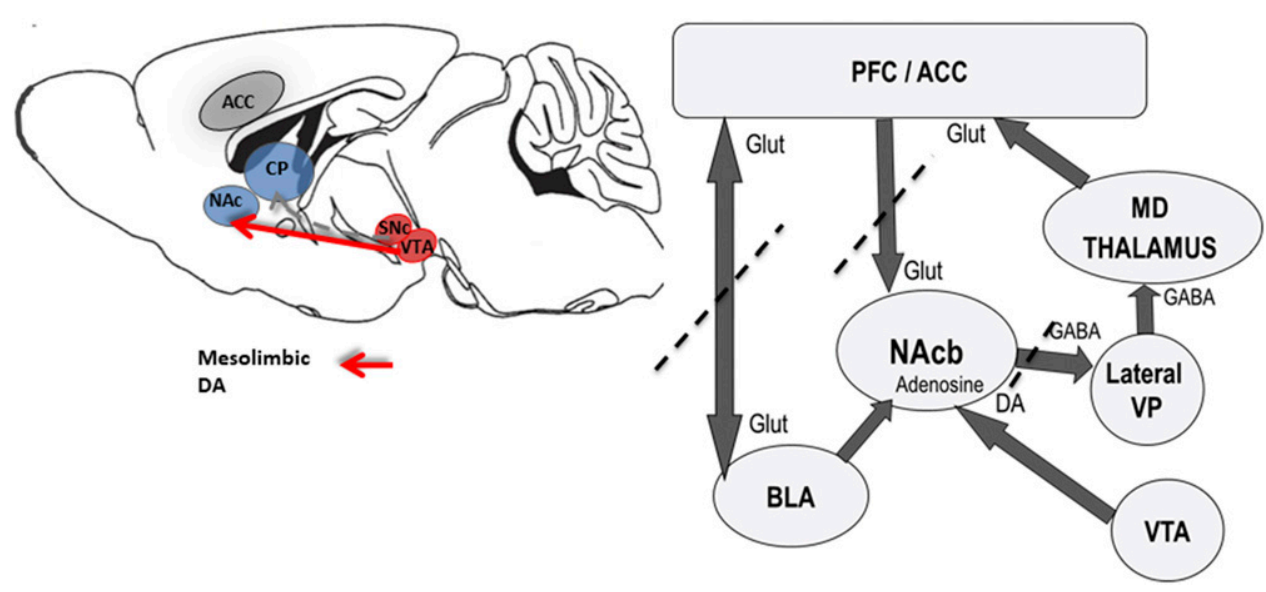

Fig. 2. Anatomic circuit diagrams depicting some of the brain structures and neurotransmitters involved in studies of effort-related decision making in rodents. Left: Schematic of the rat brain showing mesostriatal DA systems. Mesolimbic DA projection is shown with the solid arrow, whereas nigrostriatal DA projections are illustrated with dotted line. Right: This figure is a circuit diagram illustrating the limbic, cortical, striatal, and pallidal connections that are involved in effort-based choice. Furthermore, this figure illustrates the results from a group of studies employing disconnection methods. With these procedures, researchers produce combined contralateral damage to interconnected brain structures to determine whether they form part of a serial circuit that participates in a particular behavioral function (Floresco and Ghods-Sharifi, 2007: basolateral amygdala and anterior cingulate cortex; Hauber and Sommer, 2009: anterior cingulate cortex and nucleus accumbens core; Mingote et al., 2008: nucleus accumbens core and lateral ventral pallidum). 
et al., 2007). Although 5-HT selective uptake inhibitors (SSRIs) are the most commonly used antidepressants, motivational symptoms related to behavioral activation and exertion of effort are relatively resistant to treatment with SSRIs (Stahl, 2002; Cooper et al., 2014; Fava et al., 2014; Rothschild et al., 2014). Research on effortrelated motivational functions and dysfunctions involving human participants and animal models is expanding our understanding of the neurochemical basis of motivational symptoms and could ultimately lead to the development of drug treatments for motivational symptoms. Such an approach is validated by human studies showing that alterations in effort-based decision making are associated with depression (Treadway et al., 2012; Yang et al., 2014, 2016; Culbreth et al., 2018), schizophrenia (Gold et al., 2013; Culbreth et al., 2018), and Parkinson's disease (Chong et al., 2015).

The recursive interaction between human and animal studies has led to the development of formal animal models of motivational pathology that employ tasks assessing effort-based decision making (Salamone et al., 2006, 2015, 2016a,b,c; Simpson et al., 2011, 2012; Markou et al., 2013; Bailey et al., 2016; Der-Avakian et al., 2016). This research has involved an assessment of the effort-related effects in rodents of conditions associated with depression, anergia, fatigue, and apathy in humans, as well as the evaluation of potential drug treatments. One such line of inquiry has involved studies related to stress, because it is such an important factor in psychopathology. Restraint stress has been shown to induce a low-effort bias as measured with an effort-discounting task in rats (Shafiei et al., 2012), and the effort-related effects of stress involve the actions of corticotropin-releasing hormone (Bryce and Floresco, 2016).

As described above, several recent papers have used the vesicular monoamine transporter type-2 inhibitor tetrabenazine to alter effort-related choice in rodents. Tetrabenazine is used clinically to treat Huntington's disease, but it induces side effects in humans that include depression and fatigue (Frank, 2009, 2010, 2014; Guay, 2010). Moreover, tetrabenazine has been used to produce deficits in classic animal models of depression such as the forced swim test (Tadano et al., 2000; Wang et al., 2010). Considerable evidence indicates that tetrabenazine can induce a low-effort bias in rats tested on the FR5/chow-feeding choice (Nunes et al., 2013b; Yohn et al., 2016b, d,e), PROG/chow-feeding choice (Randall et al., 2015a), and T-maze barrier choice tests (Yohn et al., 2015a,b). A series of parallel control experiments has demonstrated that the effort-related effects of tetrabenazine were not due to actions such as loss of appetite, changes in preference for chow versus pellets or preference across different concentrations of sucrose, discrimination of reinforcement magnitude, or reference memory (Nunes et al., 2013; Randall et al., 2015a; Yohn et al., 2015b). In view of these findings, the tetrabenazine model appears to have potential utility for exploring possible drug strategies for human clinical use in treating effort-related motivational dysfunctions.

Because monoamine uptake inhibitors are commonly used to treat depression, albeit with limited success in terms of restoring motivational function, several recent studies have focused on the ability of monoamine uptake inhibitors with different mechanisms of action to reverse the effort-related effects of tetrabenazine. The SSRIs fluoxetine and citalopram were investigated, and neither drug was able to reverse the effects of tetrabenazine on FR5/chow-feeding choice performance (Yohn et al., 2016b,e). The NE uptake blocker desipramine also was assessed, and it also failed to reverse the effects of tetrabenazine (Yohn et al., 2016b). In contrast, several DA transport blockers have been tested, and these drugs are generally effective at attenuating the effort-related actions of tetrabenazine. The catecholamine uptake blocker bupropion (Welbutrin) is widely used as an antidepressant, and clinical studies have reported it to be more effective than SSRIs at treating fatigue symptoms (Papakostas et al., 2006; Cooper et al., 2014). Bupropion reversed the effort-based effects of tetrabenazine in rats tested on the FR5/chow-feeding choice (Nunes et al., 2013b; Yohn et al., 2016a), PROG/ chow-feeding choice (Randall et al., 2015a), and T-maze barrier choice tasks (Yohn et al., 2015b). A number of additional drugs that inhibit DA uptake have been assessed [GBR12909, PRX-14040, lisdexamfetamine (Vyvanse), methylphenidate, modafinil], and all have been reported to reverse the effort-related effects of tetrabenazine (Salamone et al., 2016c; Yohn et al., $2016 \mathrm{~b}, \mathrm{~d}, \mathrm{e})$. In this context, it is interesting to note that amphetamine, methylphenidate, and modafinil have been reported to have positive effects on motivational symptoms in patients with depression (Stotz et al., 1999; Lam et al., 2007; Ravindran et al., 2008). Furthermore, modafinil is an atypical DA transporter blocker, which has different binding characteristics than amphetamine and cocaine. The assessment of novel atypical DA transporter blockers may lead to the discovery of compounds that are useful for treating motivational dysfunction, but have relatively low abuse liability.

Another approach to studying the effort-related effects of monoamine uptake inhibitors has been to assess the ability of drugs to enhance selection of high-effort choices in otherwise untreated animals. The concurrent PROG/chow-feeding choice task has been very useful in this regard. Due to the fact that the PROG lever-pressing requirement increases as the animal continues to respond, this schedule challenges the animal with a progressively incrementing work requirement. Because the concurrently available chow essentially acts as a low-cost substitute, rats typically respond to this challenge by initially lever pressing, but then switching to the concurrently available chow during the session. This pattern of responding generates a relatively low 
baseline rate of PROG lever pressing that can be sensitive to drugs that increase behavioral activation. Several DA transport blockers can increase selection of high-effort PROG lever pressing when administered on their own, including MRZ-9547 (Sommer et al., 2014), bupropion (Randall et al., 2015b; Salamone et al., 2016a), lisdexamfetamine (Yohn et al., 2016e), PRX-14040 (Yohn et al., 2016d), and GBR12909 (Yohn et al., 2016c). These results are consistent with studies reporting that there is enhanced selection of high-effort instrumental actions in mice with knockdown of DA transporters (Cagniard et al., 2006), and in mice that have increased expression of DA D2 receptors in nucleus accumbens induced during adulthood (Trifilieff et al., 2013). However, the SSRI fluoxetine and the NE transport inhibitors desipramine and atomoxetine did not increase PROG lever pressing across a broad range of doses (Yohn et al., 2016c), and atomoxetine also did not affect performance on a ratio-discounting task (Hosking et al., 2015). Taken together with the results from the DA antagonism and DA depletion studies discussed above, these findings on the effects of DA transport inhibitors, either alone or in combination with tetrabenazine, demonstrate that there is an important dopaminergic component to the neural regulation of effort-based choice. In summary, there is strong evidence of a bidirectional pharmacological modulation of effort-related choice induced by drugs acting on DA transmission.

As reviewed above, DA is not the only neural signaling molecule involved in the regulation of effort-based choice, and several papers have reported that adenosine $\mathrm{A}_{2 \mathrm{~A}}$ antagonism and genetic deletion can reverse the effort-related effects of DA D2 receptor antagonists. Consistent with these observations, the adenosine $\mathrm{A}_{2 \mathrm{~A}}$ receptor antagonist MSX-3 has been shown to reverse the effort-related effects of tetrabenazine in rodents tested on multiple task tests of effort-related choice (Nunes et al., 2013b; Randall et al., 2015a; Yohn et al., 2015b). Recent studies in our laboratory have focused on the effort-related effects of the adenosine $\mathrm{A}_{2 \mathrm{~A}}$ receptor antagonist preladenant (Fig. 3). Preladenant is a highly selective antagonist of adenosine $\mathrm{A}_{2 \mathrm{~A}}$ receptors (Alnouri et al., 2015), with a binding affinity of less than $1 \mathrm{nM}$, and greater than 1000 -fold selectivity for $\mathrm{A}_{2 \mathrm{~A}}$ versus $\mathrm{A}_{1}$ receptors in the rat. Consistent with its high binding affinity for adenosine $A_{2 A}$ receptors, preladenant was very potent at reversing the alteration in effort-based choice induced by tetrabenazine (Fig. 3 , A and B; 0.05$0.2 \mathrm{mg} / \mathrm{kg}$ intraperitoneal; compared with $1.0-2.0 \mathrm{mg} / \mathrm{kg}$ MSX-3). MSX-3 has previously been shown to increase selection of PROG lever pressing in rats tested on the PROG/chow-feeding choice task, and preladenant was much more potent at producing this effect (Fig. 3, C and $\mathrm{D} ; 0.4 \mathrm{mg} / \mathrm{kg}$ preladenant; compared with $2.0 \mathrm{mg} / \mathrm{kg}$ MSX-3). The results of studies with MSX-3, MSX-4, istradefylline, and preladenant suggest that adenosine $\mathrm{A}_{2 \mathrm{~A}}$ antagonists have some potential for clinical use in the treatment of motivational impairments. Consistent with this idea, recent studies indicate that istradefylline can reduce fatigue symptoms in Parkinson's disease patients (Abe et al., 2016).

In addition to stress or administration of tetrabenazine as ways of producing effort-related impairments in animal models, recent studies have focused upon the role of neuroinflammation in motivational symptoms. Proinflammatory cytokines and related pathways have been implicated in depression, Parkinson's disease, schizophrenia, and other disorders, and there has been a particular focus on the association between cytokines and motivational symptoms such as anergia and fatigue (Capuron et al., 2007, 2009; Dantzer et al., 2008, 2012, 2014; Dantzer, 2009; Miller, 2009; Cattaneo et al., 2013; Felger and Treadway, 2016). Human patients are sometimes given interferon (IFN)- $\alpha$ as a treatment, and fatigue and loss of energy are reported to be the most common symptom induced by IFN- $\alpha$. Although depressed mood was reported by some patients $(30 \%-60 \%)$, fatigue and loss of energy occurred in $80 \%$ of patients receiving treatment with IFN- $\alpha$ (Miller, 2009). Moreover, patients who received IFN- $\alpha$ treatment, when compared with medically healthy people with major depression, showed less agitation and suicidal ideation, but significantly greater psychomotor slowing (Capuron et al., 2009). Some experimental studies have involved administration of the endotoxin lipopolysaccharide (LPS), which induces cytokine expression and produces the sickness behavior that is characteristic of overexpression of proinflammatory cytokines. One recent study with human participants used the effort expenditure for rewards task to assess the effects of LPS and observed that LPS did not reduce the tendency to select the higheffort option (Lasselin et al., 2017). In contrast, Draper et al. (2018) reported that LPS reduced selection of higheffort choices (squeezing a dynamometer) but did not affect reward sensitivity. In mice, Vichaya et al. (2014) demonstrated that the inflammatory response induced by LPS injection suppressed the overall exertion of effort in terms of total number of responses but left intact the relative selection of the high-effort/highreward option. Other studies in animals have involved direct administration of the proinflammatory cytokines interleukin (IL)- $1 \beta$ and IL-6. In rats tested on the FR5/chow-feeding choice task, a low-effort bias was induced by administration of IL-1 $\beta$ (Nunes et al., 2014; Yohn et al., 2016e) and IL-6 (Yohn et al., 2016a) at doses that did not alter food preference or induce fever. These effort-related effects of cytokine administration were reversed by the adenosine $\mathrm{A}_{2 \mathrm{~A}}$ antagonist MSX-3, and also by the DA transport inhibitors lisdexamfetamine and methylphenidate (Nunes et al., 2014; Yohn et al., 2016a,e). The behaviorally most effective dose of IL-6 also decreased extracellular DA in nucleus accumbens as measured by microdialysis (Yohn et al., 2016a). These studies suggest that there is important cross-talk 
A
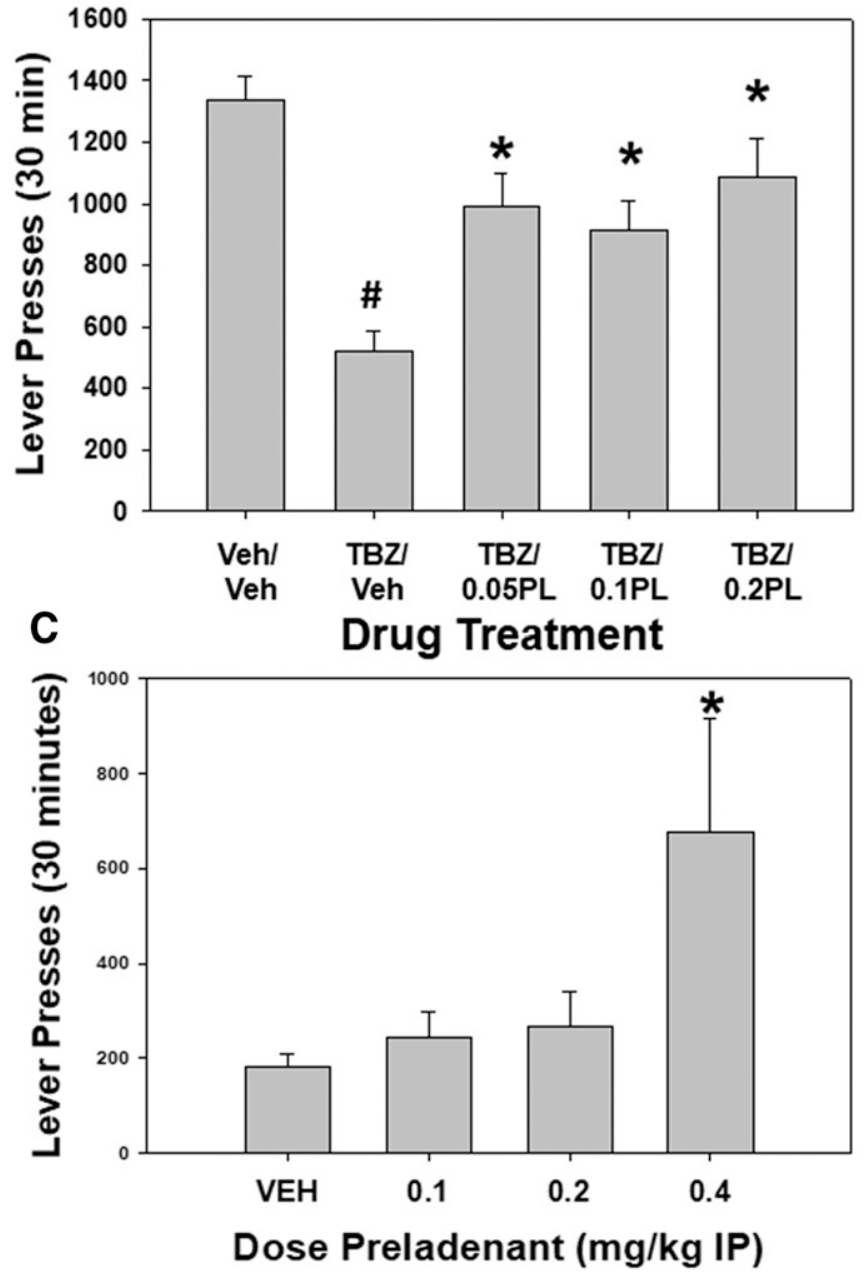

B
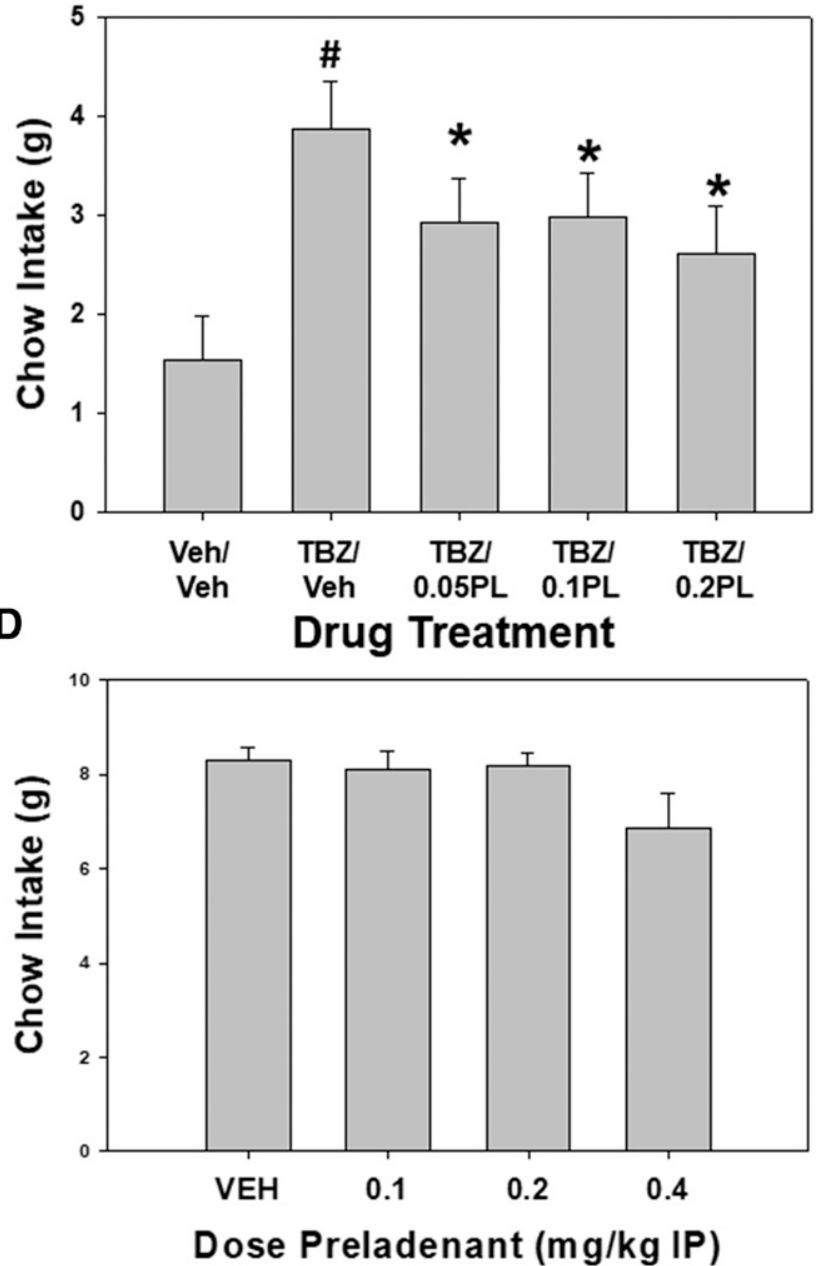

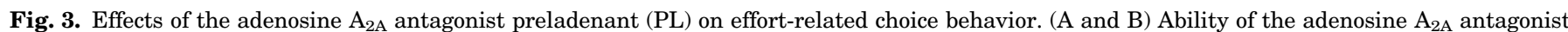

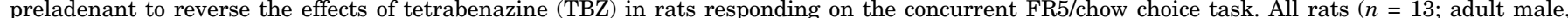

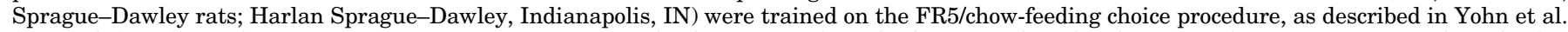

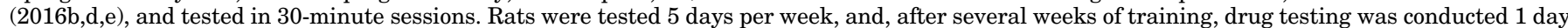

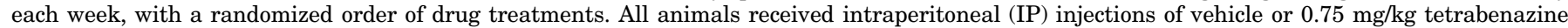

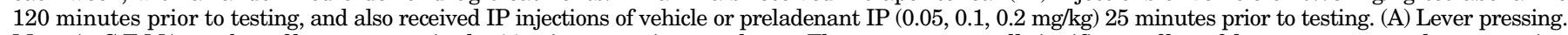

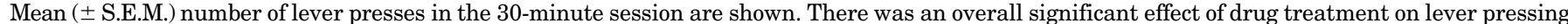

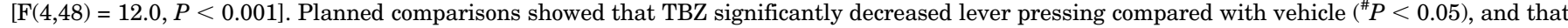

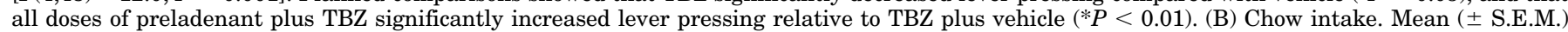

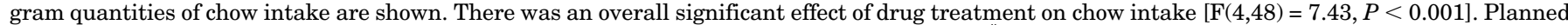

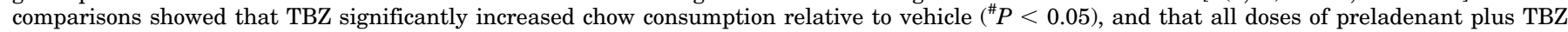

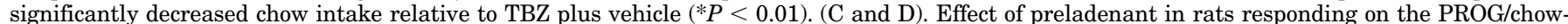

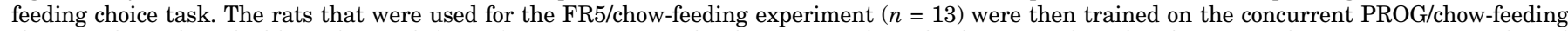

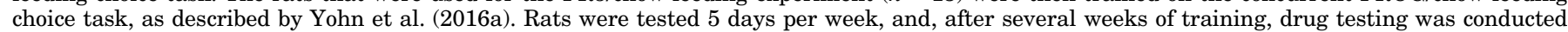

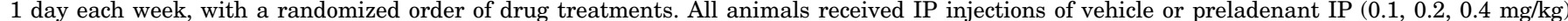

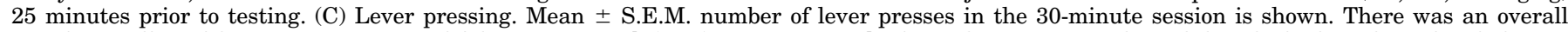

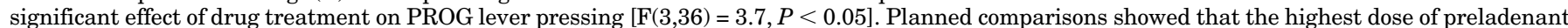

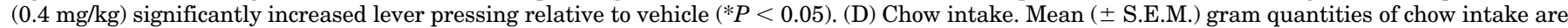

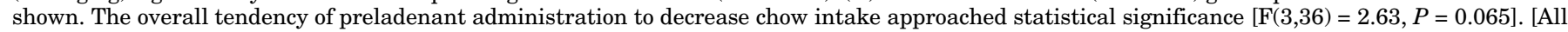
results from this figure were presented at the 2017 Society for Neuroscience meeting (Rotolo et al., 2017).]

between central neurotransmission and peripheral inflammatory responses and also illustrate possible strategies related to treatment based upon the anti-inflammatory actions of therapeutic agents.

\section{Conclusions}

As reviewed above, effort-based decision making is studied in both animal models and human research.
Although animal research has identified that mesolimbic DA is a critical component of the neural circuitry regulating effort-based choice, other transmitters and neuromodulators (GABA, adenosine) are involved, and the broader circuitry includes interconnected limbic, cortical, and pallidal structures. Research in this area has illuminated features of the neural circuitry underlying activational aspects of motivation and exertion of effort, but it also has led to the development of animal 
models that are useful for studying dysfunctions that are potentially related to aspects of human psychopathology. In fact, within the last few years, there has been an explosion of research on effort-related motivational impairments that are seen in disorders such as depression, schizophrenia, and Parkinson's disease. Of course, it needs to be emphasized that psychiatric and neurologic disorders are complex and heterogeneous conditions, and it is possible that the alterations in effort-related decision making that are seen in one disorder may be due to partially overlapping but nevertheless distinct neural mechanisms compared with those seen in other disorders (Culbreth et al., 2018). In contrast, animal studies that focus on the effects of drugs that act on specific receptors or transport proteins, or manipulations such as optogenetics that target specific cell types, are likely to be producing impairments that are relatively specific compared with human pathologies. Nevertheless, the main utility of animal models is to deconstruct complex processes and characterize the neural mechanisms underlying specific endophenotypes. This goal is consistent with the National Institutes of Health research domain criteria approach (Cuthbert and Insel, 2013), which places emphasis on symptoms and their underlying neural circuitry. Therefore, validated animal models can shed light on potential treatment strategies for specific psychiatric symptoms. Although studies of effortrelated decision making do not provide broad or general models of depression, they do provide insights into possible drug targets that warrant further exploration and development.

\section{Authorship Contributions}

Participated in research design: Salamone, Correa, Yang, Rotolo, Ferrigno.

Conducted experiments: Ferrigno, Yang, Rotolo, Presby, Salamone, Correa.

Performed data analysis: Salamone, Yang, Ferrigno, Rotolo, Presby.

Wrote or contributed to the writing of the manuscript: Salamone, Correa, Yang, Rotolo, Ferrigno, Presby.

\section{References}

Abe K, Fujita M, and Yoshikawa H (2016) Effectiveness of istradefylline for fatigue and quality of life in Parkinson's disease patients' and of their caregivers'. Advances in Parkinson's Disease 5:24-28.

Aberman JE and Salamone JD (1999) Nucleus accumbens dopamine depletions make rats more sensitive to high ratio requirements but do not impair primary food reinforcement. Neuroscience 92:545-552.

Alnouri MW, Jepards S, Casari A, Schiedel AC, Hinz S, and Müller CE (2015) Selectivity is species-dependent: characterization of standard agonists and antagonists at human, rat, and mouse adenosine receptors. Purinergic Signal 11:389-407.

Bailey MR, Goldman O, Bello EP, Chohan MO, Jeong N, Winiger V, Chun E, Schipani E, Kalmbach A, Cheer JF, et al. (2018) An interaction between serotonin receptor signaling and dopamine enhances goal-directed vigor and persistence in mice. $J$ Neurosci 38 2149-2162.

Bailey MR, Simpson EH, and Balsam PD (2016) Neural substrates underlying effort, time, and risk-based decision making in motivated behavior. Neurobiol Learn Mem 133:233-256.

Barch DM, Treadway MT, and Schoen N (2014) Effort, anhedonia, and function in schizophrenia: reduced effort allocation predicts amotivation and functional impairment. J Abnorm Psychol 123:387-397.

Bardgett ME, Depenbrock M, Downs N, Points M, and Green L (2009) Dopamine modulates effort-based decision making in rats. Behav Neurosci 123:242-251.

Berridge KC (2007) The debate over dopamine's role in reward: the case for incentive salience. Psychopharmacology (Berl) 191:391-431.
Berridge KC and Kringelbach ML (2015) Pleasure systems in the brain. Neuron 86: 646-664.

Berridge KC and Robinson TE (1998) What is the role of dopamine in reward: hedonic impact, reward learning, or incentive salience? Brain Res Brain Res Rev 28 309-369.

Berridge KC and Robinson TE (2003) Parsing reward. Trends Neurosci 26: 507-513.

Boekhoudt L, Wijbrans EC, Man JHK, Luijendijk MCM, de Jong JW, van der Plasse G, Vanderschuren LJMJ, and Adan RAH (2018) Enhancing excitability of dopamine neurons promotes motivational behaviour through increased action initiation. Eur Neuropsychopharmacol 28:171-184.

Bryce CA and Floresco SB (2016) Perturbations in effort-related decision-making driven by acute stress and corticotropin-releasing factor. Neuropsychopharmacology 41: $2147-2159$

Cagniard B, Balsam PD, Brunner D, and Zhuang X (2006) Mice with chronically elevated dopamine exhibit enhanced motivation, but not learning, for a food reward. Neuropsychopharmacology 31:1362-1370.

Capuron L, Fornwalt FB, Knight BT, Harvey PD, Ninan PT, and Miller AH (2009) Does cytokine-induced depression differ from idiopathic major depression in medically healthy individuals? J Affect Disord 119:181-185.

Capuron L, Pagnoni G, Demetrashvili MF, Lawson DH, Fornwalt FB, Woolwine B Berns GS, Nemeroff CB, and Miller AH (2007) Basal ganglia hypermetabolism and symptoms of fatigue during interferon- $\alpha$ therapy. Neuropsychopharmacology $\mathbf{3 2}$ 2384-2392.

Cattaneo A, Gennarelli M, Uher R, Breen G, Farmer A, Aitchison KJ, Craig IW, Anacker C, Zunsztain PA, McGuffin P, et al. (2013) Candidate genes expression profile associated with antidepressants response in the GENDEP study: differentiating between baseline 'predictors' and longitudinal 'targets'. Neuropsychopharmacology 38:377-385.

Caul WF and Brindle NA (2001) Schedule-dependent effects of haloperidol and amphetamine: multiple-schedule task shows within-subject effects. Pharmacol Biochem Behav 68:53-63.

Chong TT, Bonnelle V, Manohar S, Veromann KR, Muhammed K, Tofaris GK, Hu M, and Husain M (2015) Dopamine enhances willingness to exert effort for reward in Parkinson's disease. Cortex 69:40-46.

Cofer CN and Appley MH (1964) Motivation: Theory and Research, John Wiley and Sons, New York.

Collins LE, Sager TN, Sams AG, Pennarola A, Port RG, Shahriari M, and Salamone JD (2012) The novel adenosine A2A antagonist Lu AA47070 reverses the motor and motivational effects produced by dopamine D2 receptor blockade. Pharmacol Biochem Behav 100:498-505

Cooper JA, Tucker VL, and Papakostas GI (2014) Resolution of sleepiness and fatigue: a comparison of bupropion and selective serotonin reuptake inhibitors in subjects with major depressive disorder achieving remission at doses approved in the European Union. J Psychopharmacol 28:118-124.

Correa M, Carlson BB, Wisniecki A, and Salamone JD (2002) Nucleus accumbens dopamine and work requirements on interval schedules. Behav Brain Res 137: 179-187.

Correa M, Pardo M, Bayarri P, López-Cruz L, San Miguel N, Valverde O, Ledent C, and Salamone JD (2016) Choosing voluntary exercise over sucrose consumption depends upon dopamine transmission: effects of haloperidol in wild type and adenosine $\mathrm{A}_{2} \mathrm{AKO}$ mice. Psychopharmacology (Berl) 233 393-404.

Correa M, Wisniecki A, Betz A, Dobson DR, O'Neill MF, O'Neill MJ, and Salamone JD (2004) The adenosine A2A antagonist KF17837 reverses the locomotor suppression and tremulous jaw movements induced by haloperidol in rats: possible relevance to parkinsonism. Behav Brain Res 148:47-54.

Cousins MS, Atherton A, Turner L, and Salamone JD (1996) Nucleus accumbens dopamine depletions alter relative response allocation in a T-maze cost/benefit task. Behav Brain Res 74:189-197.

Cousins MS and Salamone JD (1994) Nucleus accumbens dopamine depletions in rats affect relative response allocation in a novel cost/benefit procedure. Pharmacol Biochem Behav 49:85-91.

Cousins MS, Sokolowski JD, and Salamone JD (1993) Different effects of nucleus accumbens and ventrolateral striatal dopamine depletions on instrumental response selection in the rat. Pharmacol Biochem Behav $\mathbf{4 6}$ 943-951

Culbreth AJ, Moran EK, and Barch DM (2018) Effort-cost decision-making in psychosis and depression: could a similar behavioral deficit arise from disparate psychological and neural mechanisms? Psychol Med 48:889-904.

Cuthbert BN and Insel TR (2013) Toward the future of psychiatric diagnosis: the seven pillars of RDoC. BMC Med 11:126.

Dantzer R (2009) Cytokine, sickness behavior, and depression. Immunol Allergy Clin North Am 29:247-264.

Dantzer R, Heijnen CJ, Kavelaars A, Laye S, and Capuron L (2014) The neuroimmune basis of fatigue. Trends Neurosci 37:39-46.

Dantzer R, Meagher MW, and Cleeland CS (2012) Translational approaches to treatment-induced symptoms in cancer patients. Nat Rev Clin Oncol 9: $414-426$

Dantzer R, O'Connor JC, Freund GG, Johnson RW, and Kelley KW (2008) From inflammation to sickness and depression: when the immune system subjugates the brain. Nat Rev Neurosci 9:46-56.

De Doncker W, Dantzer R, Ormstad H, and Kuppuswamy A (2018) Mechanisms of poststroke fatigue. J Neurol Neurosurg Psychiatry 89:287-293.

DeMet EM and Chicz-DeMet A (2002) Localization of adenosine A2A-receptors in rat brain with [3H]ZM-241385. Naunyn Schmiedebergs Arch Pharmacol 366:478-481.

Der-Avakian A, Barnes SA, Markou A, and Pizzagalli DA (2016) Translational assessment of reward and motivational deficits in psychiatric disorders. Curr Top Behav Neurosci 28:231-262. 
Draper A, Koch RM, van der Meer JW, Aj Apps M, Pickkers P, Husain M, and van der Schaaf ME (2018) Effort but not reward sensitivity is altered by acute sickness induced by experimental endotoxemia in humans. Neuropsychopharmacology 43: $1107-1118$.

Duffy E (1963) Activation and Behavior, John Wiley and Sons, New York.

Farrar AM, Font L, Pereira M, Mingote S, Bunce JG, Chrobak JJ, and Salamone JD (2008) Forebrain circuitry involved in effort-related choice: injections of the GABAA agonist muscimol into ventral pallidum alter response allocation in foodseeking behavior. Neuroscience 152:321-330.

Farrar AM, Pereira M, Velasco F, Hockemeyer J, Müller CE, and Salamone JD (2007) Adenosine A(2A) receptor antagonism reverses the effects of dopamine receptor antagonism on instrumental output and effort-related choice in the rat: implications for studies of psychomotor slowing. Psychopharmacology (Berl) 191: 579-586.

Farrar AM, Segovia KN, Randall PA, Nunes EJ, Collins LE, Stopper CM, Port RG Hockemeyer J, Müller CE, Correa M, et al. (2010) Nucleus accumbens and effortrelated functions: behavioral and neural markers of the interactions between adenosine A2A and dopamine D2 receptors. Neuroscience 166:1056-1067.

Fava M, Ball S, Nelson JC, Sparks J, Konechnik T, Classi P, Dube S, and Thase ME (2014) Clinical relevance of fatigue as a residual symptom in major depressive disorder. Depress Anxiety 31:250-257.

Felger JC and Treadway MT (2017) Inflammation effects on motivation and motor activity: role of dopamine. Neuropsychopharmacol 42:216-241.

Ferré S (1997) Adenosine-dopamine interactions in the ventral striatum: implications for the treatment of schizophrenia. Psychopharmacology (Berl) 133:107-120.

Ferré S, Ciruela F, Borycz J, Solinas M, Quarta D, Antoniou K, Quiroz C, Justinova Z, Lluis C, Franco R, et al. (2008) Adenosine A1-A2A receptor heteromers: new targets for caffeine in the brain. Front Biosci 13:2391-2399.

Ferré S, Ciruela F, Canals M, Marcellino D, Burgueno J, Casadó V, Hillion J, Torvinen M, Fanelli F, Benedetti Pd Pd, et al. (2004) Adenosine A2A-dopamine D2 receptor-receptor heteromers: targets for neuro-psychiatric disorders. Parkinsonism Relat Disord 10:265-271.

Ferré S, Fredholm BB, Morelli M, Popoli P, and Fuxe K (1997) Adenosine-dopamine receptor-receptor interactions as an integrative mechanism in the basal ganglia. Trends Neurosci 20:482-487.

Ferré S, Popoli P, Giménez-Llort L, Rimondini R, Müller CE, Strömberg I, Ögren SO, and Fuxe K (2001) Adenosine/dopamine interaction: implications for the treatment of Parkinson's disease. Parkinsonism Relat Disord 7:235-241.

Fischbach-Weiss S, Reese RM, and Janak PH (2018) Inhibiting mesolimbic dopamine neurons reduces the initiation and maintenance of instrumental responding. Neuroscience 372:306-315.

Font L, Mingote S, Farrar AM, Pereira M, Worden L, Stopper C, Port RG, and Salamone JD (2008) Intra-accumbens injections of the adenosine A2A agonist CGS 21680 affect effort-related choice behavior in rats. Psychopharmacology (Berl) 199:515-526.

Frank S; Huntington Study Group/TETRA-HD Investigators (2009) Tetrabenazine as anti-chorea therapy in Huntington disease: an open-label continuation study [published correction appears in BMC Neurol (2011) 11:18]. BMC Neurol 9:62.

Frank S (2010) Tetrabenazine: the first approved drug for the treatment of chorea in US patients with Huntington disease. Neuropsychiatr Dis Treat 6:657-665.

Frank S (2014) Treatment of Huntington's disease. Neurotherapeutics 11:153-160.

Fuxe K, Agnati LF, Jacobsen K, Hillion J, Canals M, Torvinen M, Tinner-Staines B, Staines W, Rosin D, Terasmaa A, et al. (2003) Receptor heteromerization in adenosine A2A receptor signaling: relevance for striatal function and Parkinson's disease. Neurology 61(Suppl 6):S19-S23.

Floresco SB (2015) The nucleus accumbens: an interface between cognition, emotion, and action. Annu Rev Psychol 66:25-52.

Floresco SB and Ghods-Sharifi S (2007) Amygdala-prefrontal cortical circuitry regulates effort-based decision making. Cereb Cortex 17:251-260.

Floresco SB, Tse MT, and Ghods-Sharifi S (2008) Dopaminergic and glutamatergic regulation of effort- and delay-based decision making. Neuropsychopharmacology 33:1966-1979.

Friedman JH, Brown RG, Comella C, Garber CE, Krupp LB, Lou JS, Marsh L, Nail L, Shulman L, and Taylor CB; Working Group on Fatigue in Parkinson's Disease (2007) Fatigue in Parkinson's disease: a review. Mov Disord 22:297-308.

Ghods-Sharifi S and Floresco SB (2010) Differential effects on effort discounting induced by inactivations of the nucleus accumbens core or shell. Behav Neurosci 124:179-191.

Gold JM, Strauss GP, Waltz JA, Robinson BM, Brown JK, and Frank MJ (2013) Negative symptoms of schizophrenia are associated with abnormal effort-cost computations. Biol Psychiatry 74:130-136.

Guay DR (2010) Tetrabenazine, a monoamine-depleting drug used in the treatment of hyperkinetic movement disorders. Am J Geriatr Pharmacother 8:331-373.

Gullion CM and Rush AJ (1998) Toward a generalizable model of symptoms in major depressive disorder. Biol Psychiatry 44:959-972.

Hamid AA, Pettibone JR, Mabrouk OS, Hetrick VL, Schmidt R, Vander Weele CM, Kennedy RT, Aragona BJ, and Berke JD (2016) Mesolimbic dopamine signals the value of work. Nat Neurosci 19:117-126.

Hart EE, Gerson JO, Zoken Y, Garcia M, and Izquierdo A (2017) Anterior cingulate cortex supports effort allocation towards a qualitatively preferred option. Eur $J$ Neurosci 46:1682-1688.

Hauber W and Sommer S (2009) Prefrontostriatal circuitry regulates effort-related decision making. Cereb Cortex 19:2240-2247.

Hosking JG, Floresco SB, and Winstanley CA (2015) Dopamine antagonism decreases willingness to expend physical, but not cognitive, effort: a comparison of two rodent cost/benefit decision-making tasks. Neuropsychopharmacology 40:1005-1015.

Howe MW, Tierney PL, Sandberg SG, Phillips PE, and Graybiel AM (2013) Prolonged dopamine signalling in striatum signals proximity and value of distant rewards. Nature 500:575-579.
Ishiwari K, Weber SM, Mingote S, Correa M, and Salamone JD (2004) Accumbens dopamine and the regulation of effort in food-seeking behavior: modulation of work output by different ratio or force requirements. Behav Brain Res 151:83-91.

Karimi S, Mesdaghinia A, Farzinpour Z, Hamidi G, and Haghparast A (2017) Reversible inactivation of the lateral hypothalamus reversed high reward choices in cost-benefit decision-making in rats. Neurobiol Learn Mem 145:135-142.

Kelley AE, Baldo BA, Pratt WE, and Will MJ (2005) Corticostriatal-hypothalamic circuitry and food motivation: integration of energy, action and reward. Physiol Behav 86:773-795

Ko D and Wanat MJ (2016) Phasic dopamine transmission reflects initiation vigor and exerted effort in an action- and region-specific manner. $J$ Neurosci 36: $2202-2211$.

Koch M, Schmid A, and Schnitzler HU (2000) Role of muscles accumbens dopamine D1 and D2 receptors in instrumental and Pavlovian paradigms of conditioned reward. Psychopharmacology (Berl) 152:67-73.

Kondo T and Mizuno Y; Japanese Istradefylline Study Group (2015) A long-term study of istradefylline safety and efficacy in patients with Parkinson disease. Clin Neuropharmacol 38:41-46.

Koob GF, Riley SJ, Smith SC, and Robbins TW (1978) Effects of 6-hydroxydopamine lesions of the nucleus accumbens septi and olfactory tubercle on feeding, locomotor activity, and amphetamine anorexia in the rat. J Comp Physiol Psychol 92: 917-927.

Krebs JR (1977) Optimal foraging: theory and experiment. Nature 268:583-584

Lam JY, Freeman MK, and Cates ME (2007) Modafinil augmentation for residua symptoms of fatigue in patients with a partial response to antidepressants. Ann Pharmacother 41:1005-1012.

Lasselin J, Treadway MT, Lacourt TE, Soop A, Olsson MJ, Karshikoff B, PauesGöranson S, Axelsson J, Dantzer R, and Lekander M (2017) Lipopolysaccharide alters motivated behavior in a monetary reward task: a randomized trial. Neuropsychopharmacology 42:801-810.

Le Heron C, Apps MAJ, and Husain M (2017) The anatomy of apathy: a neurocognitive framework for amotivated behaviour. Neuropsychologia DOI: 10.1016/j. neuropsychologia.2017.07.003 [published ahead of print].

Lex A and Hauber W (2008) Dopamine D1 and D2 receptors in the nucleus accumbens core and shell mediate Pavlovian-instrumental transfer. Learn Mem $\mathbf{1 5}$ 483-491.

Li Y, Zuo Y, Yu P, Ping X, and Cui C (2015) Role of basolateral amygdala dopamine D2 receptors in impulsive choice in acute cocaine-treated rats. Behav Brain Res 287:187-195.

López-Cruz L, Pardo M, Salamone JD, and Correa M (2014) Differences between the nonselective adenosine receptor antagonists caffeine and theophylline in motor and mood effects: studies using medium to high doses in animal models. Behav Brain Res 270:213-222.

López-Cruz L, San-Miguel N, Bayarri P, Baqi Y, Müller CE, Salamone JD, and Correa M (2016) Ethanol and caffeine effects on social interaction and recognition in mice: involvement of adenosine $\mathrm{A}_{2 \mathrm{~A}}$ and $\mathrm{A}_{1}$ receptors. Front Behav Neurosci 10:206.

Mai B, Sommer S, and Hauber W (2012) Motivational states influence effort-based decision making in rats: the role of dopamine in the nucleus accumbens. Cogn Affect Behav Neurosci 12:74-84.

Marinelli M and McCutcheon JE (2014) Heterogeneity of dopamine neuron activity across traits and states. Neuroscience 282:176-197.

Markou A, Salamone JD, Bussey TJ, Mar AC, Brunner D, Gilmour G, and Balsam P (2013) Measuring reinforcement learning and motivation constructs in experimental animals: relevance to the negative symptoms of schizophrenia. Neurosci Biobehav Rev 37:2149-2165.

McCullough LD, Cousins MS, and Salamone JD (1993) The role of nucleus accumbens dopamine in responding on a continuous reinforcement operant schedule: a neurochemical and behavioral study. Pharmacol Biochem Behav 46:581-586.

McCullough LD and Salamone JD (1992) Involvement of nucleus accumbens dopamine in the motor activity induced by periodic food presentation: a microdialysis and behavioral study. Brain Res 592:29-36.

Miller AH (2009) Norman cousins lecture: mechanisms of cytokine-induced behavioral changes: psychoneuroimmunology at the translational interface. Brain Behav Immun 23:149-158.

Mingote S, Font L, Farrar AM, Vontell R, Worden LT, Stopper CM, Port RG, Sink KS, Bunce JG, Chrobak JJ, et al. (2008) Nucleus accumbens adenosine A2A receptors regulate exertion of effort by acting on the ventral striatopallidal pathway. J Neurosci 28:9037-9046.

Mingote S, Weber SM, Ishiwari K, Correa M, and Salamone JD (2005) Ratio and time requirements on operant schedules: effort-related effects of nucleus accumbens dopamine depletions. Eur J Neurosci 21:1749-1757.

Mogenson GJ, Jones DL, and Yim CY (1980) From motivation to action: functional interface between the limbic system and the motor system. Prog Neurobiol 14: $69-97$.

Morelli M and Pinna A (2001) Interaction between dopamine and adenosine A2A receptors as a basis for the treatment of Parkinson's disease. Neurol Sci 22:71-72. Mott AM, Nunes EJ, Collins LE, Port RG, Sink KS, Hockemeyer J, Müller CE, and Salamone JD (2009) The adenosine A2A antagonist MSX-3 reverses the effects of the dopamine antagonist haloperidol on effort-related decision making in a T-maze cost/benefit procedure. Psychopharmacology (Berl) 204:103-112.

Ng E, Varaschin RK, Su P, Browne CJ, Hermainski J, Le Foll B, Pongs O, Liu F, Trudeau LE, Roder JC, et al. (2016) Neuronal calcium sensor-1 deletion in the mouse decreases motivation and dopamine release in the nucleus accumbens. Behav Brain Res 301:213-225.

Nicola SM (2016) Reassessing wanting and liking in the study of mesolimbic influence on food intake. Am J Physiol Regul Integr Comp Physiol 311:R811-R840.

Nowend KL, Arizzi M, Carlson BB, and Salamone JD (2001) D1 or D2 antagonism in nucleus accumbens core or dorsomedial shell suppresses lever pressing for food but 
leads to compensatory increases in chow consumption. Pharmacol Biochem Behav 69:373-382.

Nunes EJ, Randall PA, Estrada A, Epling B, Hart EE, Lee CA, Baqi Y, Müller CE, Correa M, and Salamone JD (2014) Effort-related motivational effects of the pro-inflammatory cytokine interleukin 1-beta: studies with the concurrent fixed ratio 5/ chow feeding choice task. Psychopharmacology (Berl) 231:727-736.

Nunes EJ, Randall PA, Hart EE, Freeland C, Yohn SE, Baqi Y, Müller CE, LópezCruz L, Correa M, and Salamone JD (2013b) Effort-related motivational effects of the VMAT-2 inhibitor tetrabenazine: implications for animal models of the motivational symptoms of depression. J Neurosci 33:19120-19130.

Nunes E.J, Randall PA, Podurgiel S, Correa M, and Salamone JD (2013a) Nucleus accumbens neurotransmission and effort-related choice behavior in food motivation: effects of drugs acting on dopamine, adenosine, and muscarinic acetylcholine receptors. Neurosci Biobehav Rev 37:2015-2025.

Nunes EJ, Randall PA, Santerre JL, Given AB, Sager TN, Correa M, and Salamone JD (2010) Differential effects of selective adenosine antagonists on the effortrelated impairments induced by dopamine D1 and D2 antagonism. Neuroscience 170:268-280.

Papakostas GI, Nutt DJ, Hallett LA, Tucker VL, Krishen A, and Fava M (2006) Resolution of sleepiness and fatigue in major depressive disorder: a comparison of bupropion and the selective serotonin reuptake inhibitors. Biol Psychiatry 60: 1350-1355.

Pardo M, López-Cruz L, San Miguel N, Salamone JD, and Correa M (2015) Selection of sucrose concentration depends on the effort required to obtain it: studies using tetrabenazine, D1, D2, and D3 receptor antagonists. Psychopharmacology (Berl) 232:2377-2391.

Pardo M, Lopez-Cruz L, Valverde O, Ledent C, Baqi Y, Müller CE, Salamone JD, and Correa M (2012) Adenosine A2A receptor antagonism and genetic deletion attenuate the effects of dopamine D2 antagonism on effort-based decision making in mice. Neuropharmacology 62:2068-2077.

Pardo M, López-Cruz L, Valverde O, Ledent C, Baqi Y, Müller CE, Salamone JD, and Correa M (2013) Effect of subtype-selective adenosine receptor antagonists on basal or haloperidol-regulated striatal function: studies of exploratory locomotion and c-Fos immunoreactivity in outbred and A(2A)R KO mice. Behav Brain Res 247: 217-226.

Parkinson JA, Dalley JW, Cardinal RN, Bamford A, Fehnert B, Lachenal G, Rudarakanchana N, Halkerston KM, Robbins TW, and Everitt BJ (2002) Nucleus accumbens dopamine depletion impairs both acquisition and performance of appetitive Pavlovian approach behaviour: implications for mesoaccumbens dopamine function. Behav Brain Res 137:149-163.

Pettibone DJ, Totaro JA, and Pflueger AB (1984) Tetrabenazine-induced depletion of brain monoamines: characterization and interaction with selected antidepressants. Eur J Pharmacol 102:425-430.

Pinna A, Wardas J, Simola N, and Morelli M (2005) New therapies for the treatment of Parkinson's disease: adenosine A2A receptor antagonists. Life Sci 77:3259-3267.

Randall PA, Lee CA, Nunes EJ, Yohn SE, Nowak V, Khan B, Shah P, Pandit S, Vemuri VK, Makriyannis A, et al. (2015a) The VMAT-2 inhibitor tetrabenazine affects effort-related decision making in a progressive ratio/chow feeding choice task: reversal with antidepressant drugs. PLoS One 9:e99320.

Randall PA, Lee CA, Podurgiel SJ, Hart E, Yohn SE, Jones M, Rowland M, LópezCruz L, Correa M, and Salamone JD (2015b) Bupropion increases selection of high effort activity in rats tested on a progressive ratio/chow feeding choice procedure: implications for treatment of effort-related motivational symptoms. Int $J$ Neuropsychopharmacol 18:1-11.

Randall PA, Nunes EJ, Janniere SL, Stopper CM, Farrar AM, Sager TN, Baqi Y, Hockemeyer J, Müller CE, and Salamone JD (2011) Stimulant effects of adenosine antagonists on operant behavior: differential actions of selective A2A and A1 antagonists. Psychopharmacology (Berl) 216:173-186.

Randall PA, Pardo M, Nunes EJ, López Cruz L, Vemuri VK, Makriyannis A, Baqi Y, Müller CE, Correa M, and Salamone JD (2012) Dopaminergic modulation of effortrelated choice behavior as assessed by a progressive ratio chow feeding choice task: pharmacological studies and the role of individual differences. PLoS One 7:e47934.

Ravindran AV, Kennedy SH, O’Donovan MC, Fallu A, Camacho F, and Binder CE (2008) Osmotic-release oral system methylphenidate augmentation of antidepressant monotherapy in major depressive disorder: results of a double-blind, ran domized, placebo-controlled trial. J Clin Psychiatry 69:87-94.

Robbins TW and Koob GF (1980) Selective disruption of displacement behaviour by lesions of the mesolimbic dopamine system. Nature 285:409-412.

Rothschild AJ, Raskin J, Wang CN, Marangell LB, and Fava M (2014) The relationship between change in apathy and changes in cognition and functional outcomes in currently non-depressed SSRI-treated patients with major depressive disorder. Compr Psychiatry 55:1-10.

Rotolo R, Ferrigno S, Yang J-H, Correa M, and Salamone JD (2017) Reversing effortrelated motivational impairments with the adenosine A2A receptor antagonist preladenant. Society for Neuroscience Online 788.06

Saddoris MP, Cacciapaglia F, Wightman RM, and Carelli RM (2015) Differential dopamine release dynamics in the nucleus accumbens core and shell reveal complementary signals for error prediction and incentive motivation. J Neurosci $\mathbf{3 5}$ $11572-11582$.

Salamone JD (1986) Different effects of haloperidol and extinction on instrumental behaviours. Psychopharmacology (Berl) 88:18-23.

Salamone JD (1987) The actions of neuroleptic drugs on appetitive instrumental behaviors, in Handbook of Psychopharmacology (Iversen LL, Iversen SD, and Snyder SH eds) pp 575-608, Plenum Press, New York.

Salamone JD (1988) Dopaminergic involvement in activational aspects of motivation: effects of haloperidol on schedule induced activity, feeding and foraging in rats. Psychobiology (Austin Tex) 16:196-206.
Salamone JD (1992) Complex motor and sensorimotor functions of striatal and accumbens dopamine: involvement in instrumental behavior processes. Psychopharmacology (Berl) 107:160-174.

Salamone JD (2010) Motor function and motivation, in Encyclopedia of Behavioral Neuroscience (Koob GF, LeMoal M, and Thompson RF eds) pp 267-272, Academic Press, Oxford.

Salamone JD, Arizzi MN, Sandoval MD, Cervone KM, and Aberman JE (2002) Dopamine antagonists alter response allocation but do not suppress appetite for food in rats: contrast between the effects of SKF 83566, raclopride, and fenfluramine on a concurrent choice task. Psychopharmacology (Berl) 160:371-380.

Salamone JD, Betz AJ, Ishiwari K, Felsted J, Madson L, Mirante B, Clark K, Font L Korbey S, Sager TN, et al. (2008a) Tremorolytic effects of adenosine A2A antagonists: implications for parkinsonism. Front Biosci 13:3594-3605

Salamone JD and Correa M (2002) Motivational views of reinforcement: implications for understanding the behavioral functions of nucleus accumbens dopamine. Behav Brain Res 137:3-25.

Salamone JD and Correa M (2012) The mysterious motivational functions of mesolimbic dopamine. Neuron 76:470-485.

Salamone JD and Correa M (2017) Motor function and motivation, in Reference Module in Neuroscience and Biobehavioral Psychology, Elsevier, DOI:10.1016/ B978-0-12-809324-5.00365-5.

Salamone JD, Correa M, Farrar A, and Mingote SM (2007) Effort-related functions of nucleus accumbens dopamine and associated forebrain circuits. Psychopharmacology (Berl) 191:461-482.

Salamone JD, Correa M, Farrar AM, Nunes EJ, and Collins LE (2010) Role of dopamineadenosine interactions in the brain circuitry regulating effort-related decision making: insights into pathological aspects of motivation. Future Neurol 5:377-392.

Salamone JD, Correa M, Mingote SM, and Weber SM (2005) Beyond the reward hypothesis: alternative functions of nucleus accumbens dopamine. Curr Opin Pharmacol 5:34-41.

Salamone JD, Correa M, Mingote SM, Weber SM, and Farrar AM (2006) Nucleus accumbens (DA) and the forebrain circuitry involved in behavioral activation and effort-related decision making: implications for understanding anergia and psychomotor slowing in depression. Curr Psychiatry Rev 2:267-280.

Salamone JD, Correa M, Yohn S, Lopez Cruz L, San Miguel N, and Alatorre L (2016a) The pharmacology of effort-related choice behavior: dopamine, depression, and individual differences. Behav Processes 127:3-17.

Salamone JD, Correa M, Yohn SE, Yang JH, Somerville M, Rotolo RA, and Presby RE (2017) Behavioral activation, effort-based choice, and elasticity of demand for motivational stimuli: basic and translational neuroscience approaches. Motiv Sci 3:208-229.

Salamone JD, Cousins MS, and Bucher S (1994a) Anhedonia or anergia? Effects of haloperidol and nucleus accumbens dopamine depletion on instrumental response selection in a T-maze cost/benefit procedure. Behav Brain Res 65:221-229.

Salamone JD, Cousins MS, McCullough LD, Carriero DL, and Berkowitz RJ (1994b) Nucleus accumbens dopamine release increases during instrumental lever pressing for food but not free food consumption. Pharmacol Biochem Behav 49:25-31.

Salamone JD, Cousins MS, and Snyder BJ (1997) Behavioral functions of nucleus accumbens dopamine: empirical and conceptual problems with the anhedonia hypothesis. Neurosci Biobehav Rev 21:341-359.

Salamone JD, Farrar AM, Font L, Patel V, Schlar DE, Nunes EJ, Collins LE, and Sager TN (2009) Differential actions of adenosine A1 and A2A antagonists on the effort-related effects of dopamine D2 antagonism. Behav Brain Res 201: $216-222$

Salamone JD, Ishiwari K, Betz AJ, Farrar AM, Mingote SM, Font L, Hockemeyer J, Müller CE, and Correa M (2008b) Dopamine/adenosine interactions related to locomotion and tremor in animal models: possible relevance to parkinsonism. Parkinsonism Relat Disord 14 (Suppl 2):S130-S134.

Salamone JD, Koychev I, Correa M, and McGuire P (2015) Neurobiological basis of motivational deficits in psychopathology. Eur Neuropsychopharmacol 25:1225-1238.

Salamone JD, Mahan K, and Rogers S (1993) Ventrolateral striatal dopamine depletions impair feeding and food handling in rats. Pharmacol Biochem Behav 44: $605-610$.

Salamone JD, Pardo M, Yohn SE, López-Cruz L, SanMiguel N, and Correa M (2016b) Mesolimbic dopamine and the regulation of motivated behavior. Curr Top Behav Neurosci 27:231-257.

Salamone JD, Steinpreis RE, McCullough LD, Smith P, Grebel D, and Mahan K (1991) Haloperidol and nucleus accumbens dopamine depletion suppress lever pressing for food but increase free food consumption in a novel food choice procedure. Psychopharmacology (Berl) 104:515-521.

Salamone JD, Wisniecki A, Carlson BB, and Correa M (2001) Nucleus accumbens dopamine depletions make animals highly sensitive to high fixed ratio requirements but do not impair primary food reinforcement. Neuroscience 105:863-870.

Salamone JD, Yohn SE, López-Cruz L, San Miguel N, and Correa M (2016c) Activational and effort-related aspects of motivation: neural mechanisms and implications for psychopathology. Brain 139:1325-1347.

Santerre JL, Nunes EJ, Kovner R, Leser CE, Randall PA, Collins-Praino LE, Lopez Cruz L, Correa M, Baqi Y, Müller CE, et al. (2012) The novel adenosine A(2A) antagonist prodrug MSX-4 is effective in animal models related to motivationa and motor functions. Pharmacol Biochem Behav 102:477-487.

Schiffmann SN, Jacobs O, and Vanderhaeghen JJ (1991) Striatal restricted adenosine A2 receptor (RDC8) is expressed by enkephalin but not by substance P neurons: an in situ hybridization histochemistry study. J Neurochem 57:1062-1067.

Schweimer J and Hauber W (2006) Dopamine D1 receptors in the anterior cingulate cortex regulate effort-based decision making. Learn Mem 13:777-782.

Segovia KN, Correa M, Lennington JB, Conover JC, and Salamone JD (2012) Changes in nucleus accumbens and neostriatal c-Fos and DARPP-32 immunoreactivity during different stages of food-reinforced instrumental training. Eur $J$ Neurosci 35:1354-1367. 
Segovia KN, Correa M, and Salamone JD (2011) Slow phasic changes in nucleus accumbens dopamine release during fixed ratio acquisition: a microdialysis study. Neuroscience 196:178-188.

Shafiei N, Gray M, Viau V, and Floresco SB (2012) Acute stress induces selective alterations in cost/benefit decision-making. Neuropsychopharmacology 37:2194-2209.

Simpson EH, Kellendonk C, Ward RD, Richards V, Lipatova O, Fairhurst S, Kandel ER, and Balsam PD (2011) Pharmacologic rescue of motivational deficit in an animal model of the negative symptoms of schizophrenia. Biol Psychiatry 69:928-935.

Simpson EH, Waltz JA, Kellendonk C, and Balsam PD (2012) Schizophrenia in translation: dissecting motivation in schizophrenia and rodents. Schizophr Bull $\mathbf{3 8}$ $1111-1117$.

Sink KS, Vemuri VK, Olszewska T, Makriyannis A, and Salamone JD (2008) Cannabinoid CB1 antagonists and dopamine antagonists produce different effects on a task involving response allocation and effort-related choice in food-seeking behavior. Psychopharmacology (Berl) 196:565-574.

Sokolowski JD, Conlan AN, and Salamone JD (1998) A microdialysis study of nucleus accumbens core and shell dopamine during operant responding in the rat. Neuroscience 86:1001-1009.

Sokolowski JD and Salamone JD (1998) The role of accumbens dopamine in lever pressing and response allocation: effects of 6-OHDA injected into core and dorsomedial shell. Pharmacol Biochem Behav 59:557-566.

Sommer S, Danysz W, Russ H, Valastro B, Flik G, and Hauber W (2014) The dopamine reuptake inhibitor MRZ-9547 increases progressive ratio responding in rats. Int J Neuropsychopharmacol 17:2045-2056.

Stahl SM (2002) The psychopharmacology of energy and fatigue. J Clin Psychiatry 63:7-8

Stauffer WR, Lak A, Kobayashi S, and Schultz W (2016) Components and characteristics of the dopamine reward utility signal. J Comp Neurol 524:1699-1711.

Stopper CM, Khayambashi S, and Floresco SB (2013) Receptor-specific modulation of risk-based decision making by nucleus accumbens dopamine. Neuropsychopharmacology 38:715-728.

Stotz G, Woggon B, and Angst J (1999) Psychostimulants in the therapy of treatment-resistant depression review of the literature and findings from a retrospective study in 65 depressed patients. Dialogues Clin Neurosci 1:165-174.

Svenningsson P, Le Moine C, Fisone G, and Fredholm BB (1999) Distribution, biochemistry and function of striatal adenosine A2A receptors. Prog Neurobiol 59 355-396.

Tadano T, Nakagawasai O, Niijima F, Tan-No K, and Kisara K (2000) The effects of traditional tonics on fatigue in mice differ from those of the antidepressant imipramine: a pharmacological and behavioral study. Am J Chin Med 28:97-104.

Tanra AJ, Kagaya A, Okamoto Y, Muraoka M, Motohashi N, and Yamawaki S (1995) TJS-010, a new prescription of oriental medicine, antagonizes tetrabenazineinduced suppression of spontaneous locomotor activity in rats. Prog Neuropsychopharmacol Biol Psychiatry 19:963-971.

Treadway MT, Bossaller NA, Shelton RC, and Zald DH (2012) Effort-based decisionmaking in major depressive disorder: a translational model of motivational anhedonia. J Abnorm Psychol 121:553-558.

Treadway MT and Zald DH (2011) Reconsidering anhedonia in depression: lessons from translational neuroscience. Neurosci Biobehav Rev 35:537-555.

Trifilieff P, Feng B, Urizar E, Winiger V, Ward RD, Taylor KM, Martinez D, Moore H, Balsam PD, Simpson EH, et al. (2013) Increasing dopamine D2 receptor expression in the adult nucleus accumbens enhances motivation. Mol Psychiatry 18 $1025-1033$

Tylee A, Gastpar M, Lépine JP, and Mendlewicz J; DEPRES Steering Committee (1999) DEPRES II (Depression Research in European Society II): a patient survey of the symptoms, disability and current management of depression in the community. Int Clin Psychopharmacol 14:139-151.

van den Bos R, van der Harst J, Jonkman S, Schilders M, and Spruijt B (2006) Rats assess costs and benefits according to an internal standard. Behav Brain Res 171 350-354.

Vichaya EG, Hunt SC, and Dantzer R (2014) Lipopolysaccharide reduces incentive motivation while boosting preference for high reward in mice. Neuropsychopharmacology 39:2884-2890.

Wakabayashi KT, Fields HL, and Nicola SM (2004) Dissociation of the role of nucleus accumbens dopamine in responding to reward-predictive cues and waiting for reward. Behav Brain Res 154:19-30.

Wallace M, Singer G, Finlay J, and Gibson S (1983) The effect of 6-OHDA lesions of the nucleus accumbens septum on schedule-induced drinking, wheelrunning and corticosterone levels in the rat. Pharmacol Biochem Behav 18:129-136.

Walton ME, Bannerman DM, Alterescu K, and Rushworth MFS (2003) Functional specialization within medial frontal cortex of the anterior cingulate for evaluating effort-related decisions. J Neurosci 23:6475-6479.
Walton ME, Bannerman DM, and Rushworth MF (2002) The role of rat medial frontal cortex in effort-based decision making. $J$ Neurosci 22:10996-11003.

Wang H, Chen X, Li Y, Tang TS, and Bezprozvanny I (2010) Tetrabenazine is neuroprotective in Huntington's disease mice. Mol Neurodegener 5:18

Whitton AE, Treadway MT, and Pizzagalli DA (2015) Reward processing dysfunction in major depression, bipolar disorder and schizophrenia. Curr Opin Psychiatry 28: $7-12$

Winstanley CA and Floresco SB (2016) Deciphering decision making: variation in animal models of effort- and uncertainty-based choice reveals distinct neural circuitries underlying core cognitive processes. J Neurosci 36:12069-12079.

Winstanley CA, Theobald DE, Dalley JW, and Robbins TW (2005) Interactions between serotonin and dopamine in the control of impulsive choice in rats: therapeutic implications for impulse control disorders. Neuropsychopharmacology 30:669-682

Wood J, Simon NW, Koerner FS, Kass RE, and Moghaddam B (2017) Networks of VTA neurons encode real-time information about uncertain numbers of actions executed to earn a reward. Front Behav Neurosci 11:140.

Worden LT, Shahriari M, Farrar AM, Sink KS, Hockemeyer J, Müller CE, and Salamone JD (2009) The adenosine A2A antagonist MSX-3 reverses the effortrelated effects of dopamine blockade: differential interaction with D1 and D2 family antagonists. Psychopharmacology (Berl) 203:489-499.

Wyvell CL and Berridge KC (2000) Intra-accumbens amphetamine increases the conditioned incentive salience of sucrose reward: enhancement of reward "wanting" without enhanced "liking" or response reinforcement. J Neurosci 20: 8122-8130.

Yang XH, Huang J, Lan Y, Zhu CY, Liu XQ, Wang YF, Cheung EF, Xie GR, and Chan RC (2016) Diminished caudate and superior temporal gyrus responses to effortbased decision making in patients with first-episode major depressive disorder. Prog Neuropsychopharmacol Biol Psychiatry 64:52-59.

Yang XH, Huang J, Zhu CY, Wang YF, Cheung EF, Chan RC, and Xie GR (2014) Motivational deficits in effort-based decision making in individuals with subsyndromal depression, first-episode and remitted depression patients. Psychiatry Res 220:874-882.

Yohn SE, Alberati D, Correa M, and Salamone JD (2017a) Assessment of a glycine uptake inhibitor in animal models of effort-related choice behavior: implications for motivational dysfunctions. Psychopharmacology (Berl) 234:1525-1534.

Yohn SE, Arif Y, Haley A, Tripodi G, Baqi Y, Müller CE, Miguel NS, Correa M, and Salamone JD (2016a) Effort-related motivational effects of the proinflammatory cytokine interleukin-6: pharmacological and neurochemical characterization. Psychopharmacology (Berl) 233:3575-3586.

Yohn SE, Collins SL, Contreras-Mora HM, Errante EL, Rowland MA, Correa M and Salamone JD (2016b) Not all antidepressants are created equal: differential effects of monoamine uptake inhibitors on effort-related choice behavior. Neuropsychopharmacology 41:686-694.

Yohn SE, Errante EE, Rosenbloom-Snow A, Somerville M, Rowland M, Tokarski K, Zafar N, Correa M, and Salamone JD (2016c) Blockade of uptake for dopamine, but not norepinephrine or 5-HT, increases selection of high effort instrumental activity: implications for treatment of effort-related motivational symptoms in psychopathology. Neuropharmacology 109:270-280.

Yohn SE, Gogoj A, Haque A, Lopez-Cruz L, Haley A, Huxley P, Baskin P, Correa M, and Salamone JD (2016d) Evaluation of the effort-related motivational effects of the novel dopamine uptake inhibitor PRX-14040. Pharmacol Biochem Behav 148: 84-91.

Yohn SE, Gorka D, Mistry A, Collins S, Qian E, Correa M, Manchanda A, Bogner $\mathrm{RH}$, and Salamone JD (2017b) Oral ingestion and intraventricular injection of curcumin attenuates the effort-related effects of the VMAT-2 inhibitor tetrabenazine: implications for motivational symptoms of depression. $J$ Nat Prod 80: 2839-2844.

Yohn SE, Lopez-Cruz L, Hutson PH, Correa M, and Salamone JD (2016e) Effects of isdexamfetamine and s-citalopram, alone and in combination, on effort-related choice behavior in the rat. Psychopharmacology (Berl) 233:949-960.

Yohn SE, Santerre JL, Nunes EJ, Kozak R, Podurgiel SJ, Correa M, and Salamone JD (2015b) The role of dopamine D1 receptor transmission in effort-related choice behavior: effects of D1 agonists. Pharmacol Biochem Behav 135:217-226.

Yohn SE, Thompson C, Randall PA, Lee CA, Müller CE, Baqi Y, Correa M, and Salamone JD (2015a) The VMAT-2 inhibitor tetrabenazine alters effort-related decision making as measured by the T-maze barrier choice task: reversal with the adenosine A2A antagonist MSX-3 and the catecholamine uptake blocker bupropion. Psychopharmacology (Berl) 232:1313-1323

Zweifel LS, Parker JG, Lobb CJ, Rainwater A, Wall VZ, Fadok JP, Darvas M, Kim MJ, Mizumori SJ, Paladini CA et al (2009) Disruption of NMDAR-dependent burst firing by dopamine neurons provides selective assessment of phasic dopamine-dependent behavior. Proc Natl Acad Sci USA 106:7281-7288. 